\title{
EL CRÉDITO AL SECTOR PRIVADO EN ESPAÑA: DEL CRECIMIENTO DESBORDADO A LA FUERTE RESTRICCIÓN
}

\author{
POR \\ Antonio CALVO BERNARDINO y \\ Jesús PAÚL GUTIÉRREZ ${ }^{1}$
}

\section{RESUMEN}

La fuerte contracción del crédito al sector privado constituye un elemento característico de la profunda crisis que actualmente atraviesa la economía española. Este comportamiento no es algo sorprendente, dado que es conocida la existencia de una fuerte correlación positiva entre los ciclos económicos y los ciclos crediticios, tal y como ha sido ampliamente documentado en la literatura económica. Con el fin de comprender la fuerte restricción crediticia a la que en el momento presente se enfrentan las empresas no financieras y las familias españolas, en este artículo se analiza el último ciclo del crédito que se ha registrado en nuestra economía. Se delimita su longitud e intensidad y se compara con otros ciclos crediticios registrados en décadas pasadas. Tras estudiar el comportamiento del crédito en la fase alcista del ciclo y los principales desequilibrios acumulados en ella, centramos el análisis en su fase bajista, evaluando los factores de oferta y demanda crediticia que están incidiendo en la contracción del crédito. Un especial énfasis se da al papel que las entidades bancarias de carácter social han tenido en este proceso cíclico del crédito.

Palabras clave: crédito bancario al sector privado, ciclo crediticio, demanda y oferta de crédito, entidades bancarias de carácter social.

\footnotetext{
1 Antonio Calvo Bernardo: Universidad CEU San Pablo. Dirección de correo electrónico: acalvo@ceu.es Jesús Paúl Gutiérrez, Universidad CEU San Pablo. Dirección de correo electrónico: pagut@ceu.es
}

REVESCO No 109 - MONOGRÁFICO: La financiación complementaria y la respuesta de la economía social: la situación del "des-crédito" bajo la crisis financiera -

ISSN: 1885-8031 - www.ucm.es/info/revesco

http://dx.doi.org/10.5209/rev_REVE.2012.v109.40651

Fecha de recepción: 19/09/2012

Fecha de aceptación: 19/10/2012 
Claves Econlit: E32; E51; G21

PRIVATE SECTOR CREDIT IN SPAIN: FROM BOOM TO BUST

\begin{abstract}
The deep crisis in the Spanish economy is characterized by the existence of a sharp contraction in private sector credit. This credit behavior is not surprising, since it is known that there is a strong positive correlation between economic cycles and credit cycles, as has been well documented in the literature. In order to understand the strong credit restrictions which Spanish non-financial firms and households are facing at present, this article analyses the last credit cycle that has occurred in Spanish economy. It is defined its length and intensity and compared with other credit cycles in past decades. After studying the behavior of credit in the expansion phase of the cycle and the major imbalances accumulated in it, we focus the analysis in the recession phase, assessing the supply and demand factors that are affecting credit crunch. A special emphasis is given to the role that social banking institutions have had in this cyclical process of credit.
\end{abstract}

Key words: bank credit to private sector, credit cycle, credit demand and supply, social banking institutions.

\title{
1. INTRODUCCIÓN
}

La crisis financiera global, y la posterior transformación en crisis de la deuda soberana en el seno de la UEM, ha afectado de forma especialmente acusada a la economía española, que se ha mostrado muy vulnerable como consecuencia de los desequilibrios acumulados durante el largo período de expansión que registró desde mediados de los noventa hasta 2007. España no sólo está inmersa en una profunda recesión económica, con una incidencia muy negativa en el mercado de trabajo, que ha hecho que el paro vuelva a situarse en cifras récord, sino que se enfrenta a una crisis financiera con dos peligrosas vertientes, una crisis de deuda que está impidiendo a las administraciones públicas financiarse a tipos de interés que permitan la sostenibilidad de sus cuentas, y una crisis bancaria que ha obligado a nacionalizar

REVESCO N 109 - MONOGRÁFICO: La financiación complementaria y la respuesta de la economía social: la situación del "des-crédito" bajo la crisis financiera -

ISSN: 1885-8031 - www.ucm.es/info/revesco 
entidades y a acudir a la ayuda financiera de la Unión Europea para su recapitalización, y conseguir así una solución ordenada de la crisis bancaria.

Una de las características de la economía española durante este período de crisis está siendo la contracción del crédito al sector privado. Este hecho es especialmente relevante para el funcionamiento de nuestra economía, dado que en España, al igual que en el resto de la zona del euro y a diferencia de Estados Unidos, los préstamos bancarios constituyen la principal fuente de financiación externa. En concreto, en 2011 los préstamos de las entidades crediticias residentes representaban en torno al $80 \%$ del total de la financiación del conjunto de los hogares y de las sociedades no financieras.

Esta contracción del crédito, en un momento de recesión económica, no es algo sorprendente, dado que es conocida la existencia de una fuerte correlación positiva entre actividad económica y crédito al sector privado ${ }^{2}$. En las fases de expansión de la actividad económica el aumento de la demanda de bienes y servicios de las empresas no financieras y el de las rentas de los hogares impulsa la demanda crediticia, a la vez que las entidades financieras también tienen incentivos para incrementar la oferta, resultado de lo cual las tasas de crecimiento del crédito se aceleran. Por el contrario, cuando la actividad económica se desacelera, y se deterioran las perspectivas económicas, el crecimiento del crédito se reduce. En definitiva, se puede afirmar que el ciclo económico suele ir acompañado de un ciclo de crédito.

En ocasiones, como lo acontecido en España desde mediados de la década de los noventa, en la fase expansiva del ciclo se asiste a un "boom crediticio" o fase de crecimiento excesivo del crédito en la que se acumulan una serie de problemas (un sesgo inadecuado en la estructura del endeudamiento bancario, un excesivo endeudamiento con el exterior o la reducción de los controles sobre la calidad del crédito), que provocan un importante deterioro de la estabilidad financiera de las entidades crediticias y que suelen finalizar en períodos de fuerte restricción crediticia y de crisis bancarias (Alberola y Berganza, 2007).

\footnotetext{
2 Un análisis de los factores que hacen que la actividad bancaria tenga un carácter procíclico puede encontrarse en Gual (2009).
}

REVESCO No 109 - MONOGRÁFICO: La financiación complementaria y la respuesta de la economía social: la situación del "des-crédito" bajo la crisis financiera -

ISSN: 1885-8031 - www.ucm.es/info/revesco 
Ahora bien, la comprensión de la actual fase de decrecimiento del crédito exige tener en cuenta el anterior período de expansión. Dicho de otro modo, no se puede entender la actual fase bajista del ciclo crediticio sin tener en cuenta la anterior de crecimiento desbordado y acumulación de desequilibrios.

Precisamente, el análisis del último ciclo crediticio registrado en la economía española constituye el objetivo central del presente artículo. En primer lugar, se delimita su longitud e intensidad, y se compara con los registrados en nuestra economía desde inicios de la década de los setenta. A continuación, se analiza el comportamiento del crédito en la fase alcista del ciclo y los principales desequilibrios acumulados en ella. Posteriormente, nos centramos en el análisis de la fase bajista del ciclo. En el apartado sexto, por su parte, trataremos de responder al papel que han cumplido las entidades bancarias de carácter social en este proceso cíclico del crédito. Finalizamos nuestro trabajo con la consideración de los factores de oferta y demanda crediticia que han incidido en ese comportamiento del crédito.

\section{LOS CICLOS CREDITICIOS DE LA ECONOMÍA ESPAÑOLA}

En las cuatro últimas décadas, el crédito de las entidades de crédito al sector privado no financiero de la economía española ha estado sometido a fuertes fluctuaciones cíclicas, tanto si se considera en términos nominales como si se hace en términos reales. En efecto, como se puede observar en el gráfico 1, en nuestra economía se han registrado períodos de elevado crecimiento del crédito bancario al sector privado seguidos de períodos de muy moderado crecimiento, o incluso de decrecimiento si consideramos su evolución en términos reales.

La existencia de fuertes fluctuaciones en el crecimiento del crédito al sector privado no es una característica exclusiva de la economía española. También las principales economías desarrolladas han estado sujetas a acusados ciclos crediticios en los que se han alternado fases de rápido aumento del crédito al sector privado con períodos de muy bajo crecimiento o incluso descenso ${ }^{3}$.

\footnotetext{
${ }^{3}$ Para un análisis de los ciclos crediticios registrados en las principales economías avanzadas en las últimas décadas véase Anguren (2012) y BCE (2012).
}

REVESCO No 109 - MONOGRÁFICO: La financiación complementaria y la respuesta de la economía social: la situación del "des-crédito" bajo la crisis financiera -

ISSN: 1885-8031 - www.ucm.es/info/revesco 
La simple observación del Gráfico 1 nos permite comprobar que, a mediados de la década de los años noventa, el comportamiento del crédito al sector privado experimentó un cambio de tendencia y cómo se produjo un rápido aumento en sus tasas de crecimiento, tanto en términos nominales como reales. No obstante, con el fin de poder identificar de manera sencilla los diferentes ciclos crediticios registrados en la economía española, y en particular el último, que como ya hemos indicado es el objeto central de estudio en el presente artículo, hemos procedido a estandarizar la serie de las tasas de crecimiento interanual del crédito bancario en términos reales (véase el gráfico 2).

Gráfico 1. Crédito de las entidades de crédito residentes al sector privado no financiero

\section{Tasas de Variación Nominal y Real}

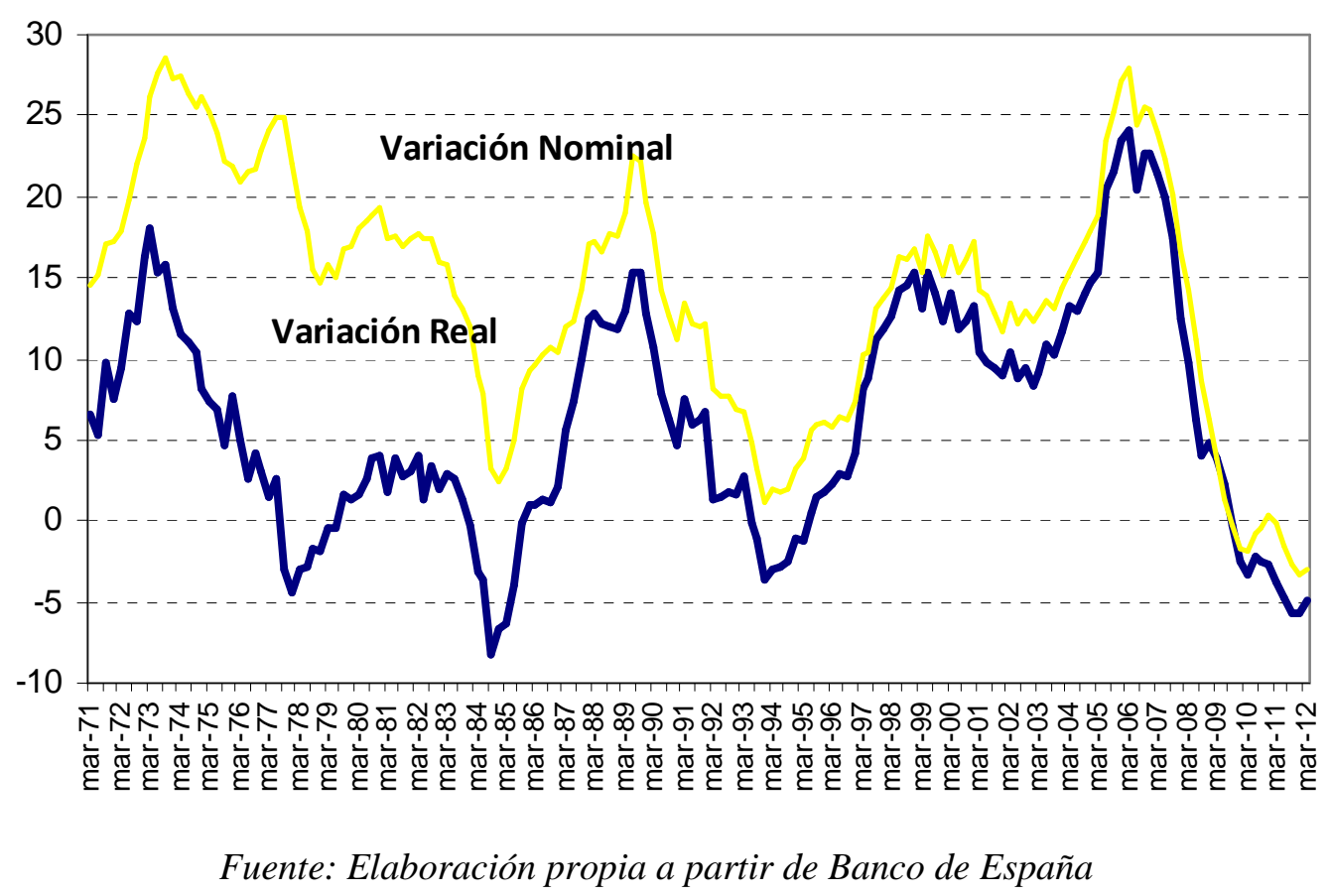

Para su estudio, vamos a considerar la existencia de tres posibles fases o estados en la evolución del crédito:

REVESCO No 109 - MONOGRÁFICO: La financiación complementaria y la respuesta de la economía social: la situación del "des-crédito" bajo la crisis financiera -

ISSN: 1885-8031 - www.ucm.es/info/revesco 
a) Fases alcistas. Aquellas en las que el crecimiento del crédito resulta relativamente elevado. En concreto, estableceremos que la economía se encuentra en una fase alcista cuando el valor medio de la variable estandarizada sea superior a $0,5^{4}$.

b) Fases intermedias, aquellas en las que el valor medio de la variable estandarizada se sitúa en el intervalo $(0,5,-0,5)$.

c) Fases bajistas, aquellas en las que el valor medio de la variable estandarizada es inferior a $-0,5$.

Gráfico 2. Crédito de las entidades de crédito residentes al sector privado no financiero

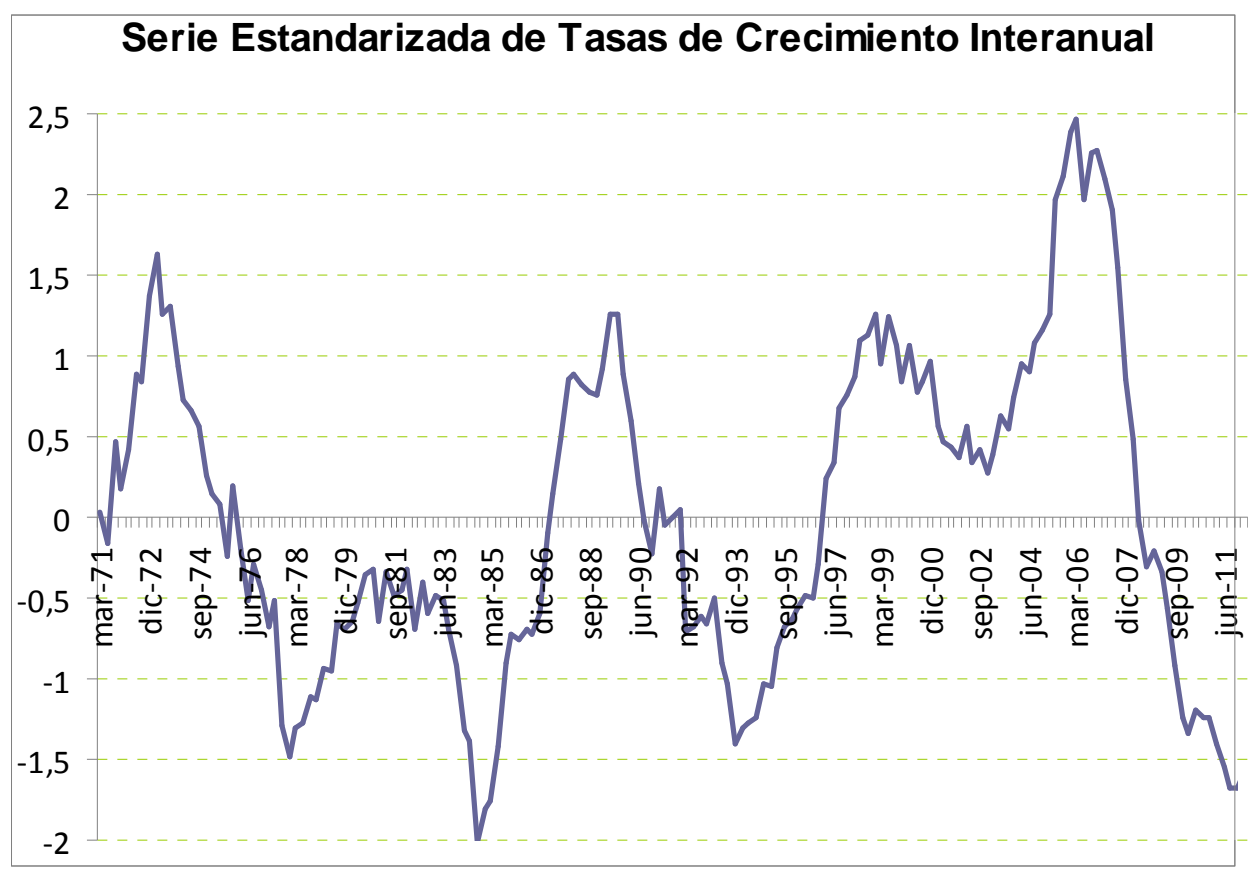

Fuente: Elaboración propia a partir de Banco de España

Establecidos los anteriores criterios para diferenciar las distintas fases de comportamiento del crédito, el inicio de la fase alcista del último ciclo crediticio se sitúa en septiembre de 1997, y aunque en el período junio de 2001 a marzo de 2003 el crecimiento del crédito se moderó, podemos considerar que esta fase de elevado crecimiento del crédito se mantuvo hasta diciembre de 2007.

\footnotetext{
${ }^{4}$ Dado que estamos considerando una serie estandarizada, un valor de uno representa una desviación típica por encima del crecimiento medio del crédito de la serie original. Como la desviación típica para el período considerado presenta un valor de 7,2 y la media del período es 6,3, el valor de la serie original sería de 13,5.
}

REVESCO No 109 - MONOGRÁFICO: La financiación complementaria y la respuesta de la economía social: la situación del "des-crédito" bajo la crisis financiera -

ISSN: 1885-8031 - www.ucm.es/info/revesco 
Atendiendo a los criterios anteriormente establecidos, la fase bajista del último ciclo crediticio se inició en junio de 2009, manteniéndose en la actualidad, sin que existan perspectivas de una reversión rápida en este comportamiento de descenso en el crédito concedido al sector privado.

\section{LA FASE ALCISTA DEL ÚlTIMO CICLO CREDITICIO DE LA ECONOMÍA ESPAÑOLA}

Cuando se inició la crisis financiera global en 2007 la economía española se encontraba en el punto de inflexión de la fase expansiva del ciclo crediticio más intenso y prolongado que ha registrado en las últimas décadas.

Tal y como se puede observar en el Gráfico 1, a partir de mediados de la década de los noventa se produjo una progresiva aceleración en el crecimiento del crédito, que se hizo especialmente intensa a partir de 2003 y que alcanzó su máximo a inicios de 2006, con una tasa de crecimiento real del crédito al sector privado no financiero en torno al $25 \%$, la cual era muy superior (alrededor de 10 puntos) a las tasas de crecimiento máximas alcanzadas en los anteriores ciclos crediticios.

Gráfico 3. Préstamos de las entidades de crédito residentes al sector privado no financiero

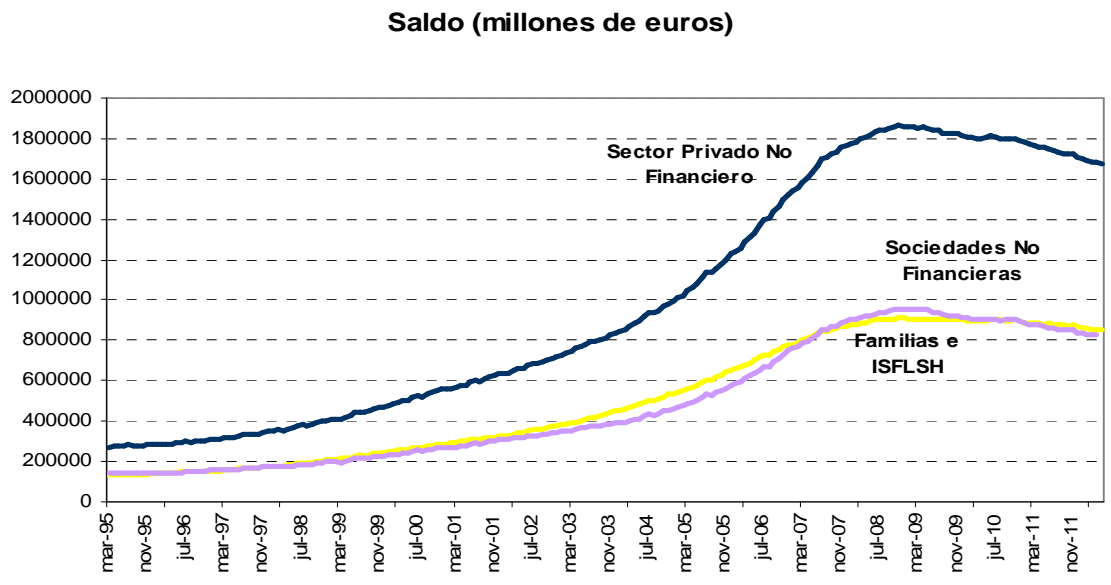

REVESCO No 109 - MONOGRÁFICO: La financiación complementaria y la respuesta de la economía social: la situación del "des-crédito" bajo la crisis financiera -

ISSN: 1885-8031 - www.ucm.es/info/revesco 


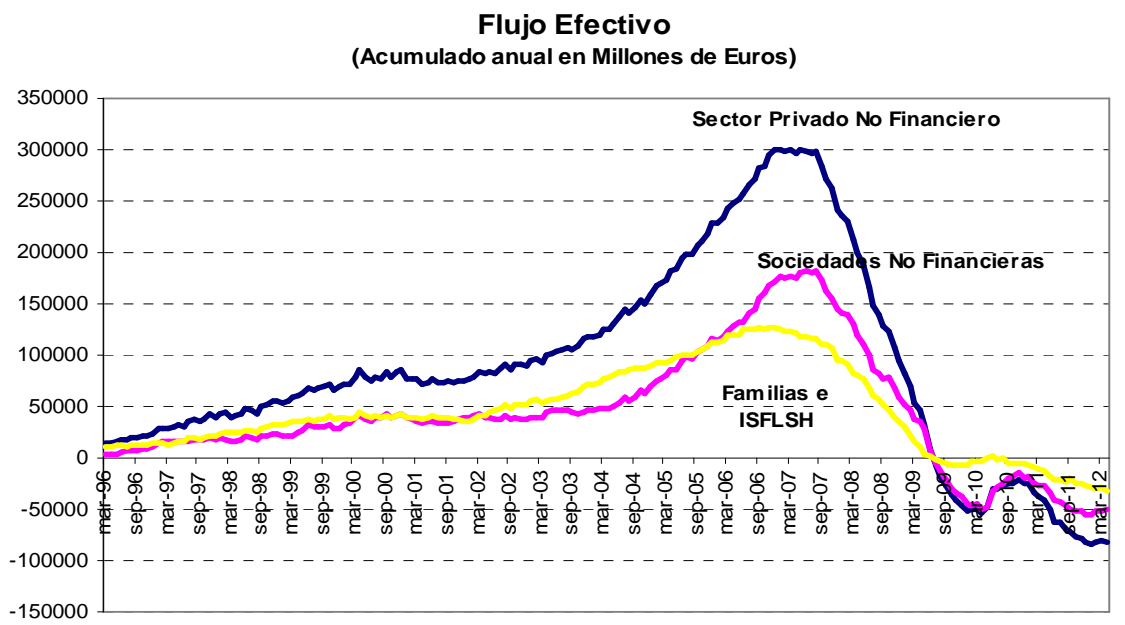

Tasas de variación interanual

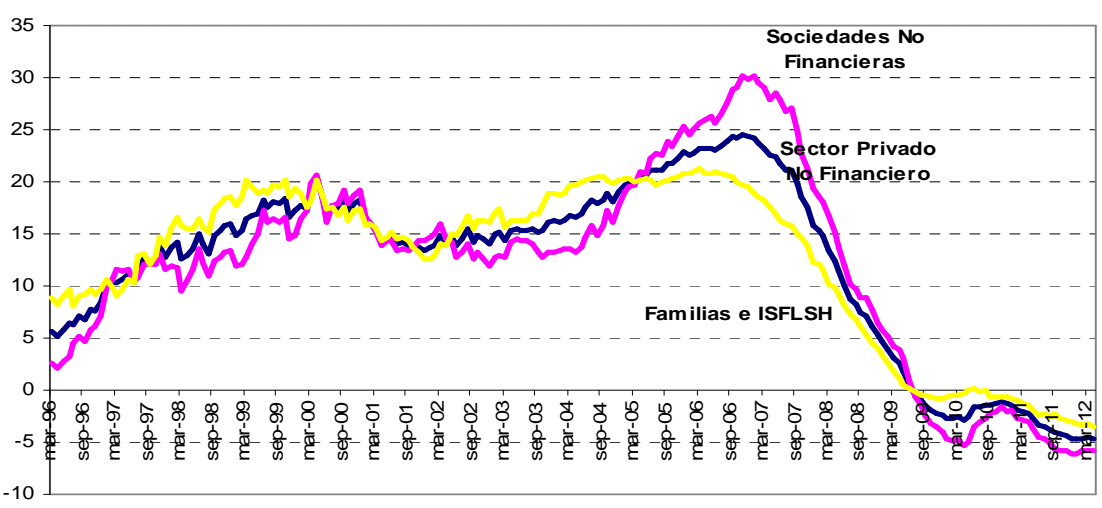

Fuente: Elaboración propia a partir de Banco de España

Junto a su intensidad, en la fase expansiva de este ciclo crediticio destaca su duración, de más de diez años, lo cual contrasta con anteriores ciclos expansivos cuya duración fue en torno a dos o tres años 5 .

Algunos datos adicionales pueden darnos una idea más aproximada de lo que supuso este ciclo crediticio alcista (véase Gráfico 3):

- En septiembre de 1997, fecha en la que hemos establecido el inicio de la fase expansiva del último ciclo crediticio, el stock de crédito concedido a hogares y

\footnotetext{
${ }^{5}$ Según las estimaciones de Anguren (2012), la pasada fase alcista del crédito registrada en España sería la más prolongada entre todos los países desarrollados desde los años setenta.
}

REVESCO No 109 - MONOGRÁFICO: La financiación complementaria y la respuesta de la economía social: la situación del "des-crédito" bajo la crisis financiera -

ISSN: 1885-8031 - www.ucm.es/info/revesco 
empresas no financieras era de 334 mil millones de euros (66\% del PIB). En diciembre de 2007, una vez iniciada la crisis financiera global, y momento en el que damos por concluido el ciclo crediticio alcista, el stock crediticio al sector privado se había más que quintuplicado, elevándose a 1,8 billones de euros (167\% del PIB).

- El flujo efectivo crediticio anual al sector privado (calculado como variación del stock crediticio en un período de cuatro trimestres) en septiembre de 1997 era aproximadamente de 36 mil millones de euros, mientras que en diciembre de 2007 se aproximaba a los 250.000 millones, lo que supone que, en el momento álgido de la fase alcista del ciclo crediticio, el incremento anual del stock de crédito al sector privado equivalía al $25 \%$ del PIB anual.

- La tasa media de crecimiento nominal del crédito al sector privado en el período transcurrido desde septiembre de 1997 hasta diciembre de 2007 fue del 17,6\% y, en el período enero de 2003 a agosto de 2007, la tasa se aproximó al 20\%.

Si descomponemos su evolución por sectores institucionales con el fin de evaluar si se vieron afectados de manera diferente por el boom crediticio, comprobamos que el dirigido a empresas no financieras y a familias e ISFLSH registró un comportamiento totalmente similar. En efecto, su tasa de crecimiento medio anual a empresas no financieras, desde septiembre de 1997 a diciembre de 2007, fue de 17,6\%, al igual que el concedido a las familias. Tan sólo cabe destacar el comportamiento diferenciado en los dos años previos al estallido de la crisis, período en el que el crédito a empresas creció a tasas próximas al 30\%, mientras que el crédito a las familias ya había iniciado una senda de desaceleración.

Por otra parte, el análisis detallado según sus distintas finalidades del crédito a otros sectores residentes constituye un elemento central para comprender el boom registrado en el prolongado período de expansión previo a que se iniciara la crisis financiera global.

Como pone de manifiesto el Cuadro 1, durante la fase expansiva del último ciclo crediticio, el crédito destinado a financiar actividades productivas registró un crecimiento medio anual del $16,6 \%$. No obstante, dentro de una tónica general de elevado aumento del concedido a todos los sectores productivos, es preciso diferenciar entre las tasas de crecimiento registradas por los sectores ligados al sector de la construcción e inmobiliario y el

REVESCO No 109 - MONOGRÁFICO: La financiación complementaria y la respuesta de la economía social: la situación del "des-crédito" bajo la crisis financiera -

ISSN: 1885-8031 - www.ucm.es/info/revesco 
resto de sectores productivos. Así, el crédito al sector de la construcción registró un crecimiento medio anual del $18,8 \%$ y el concedido a los servicios inmobiliarios fue del $33,2 \%$, llegando en los momentos álgidos (finales de 2006) a crecer a tasas del 35\% y 50\%, respectivamente.

Cuadro 1. Crédito de las entidades de crédito residentes a otros sectores residentes detalle por finalidades

\begin{tabular}{|c|c|c|c|c|c|c|}
\hline & \multicolumn{3}{|c|}{ FASE ALCISTA DEL CICLO CREDITICIO } & \multicolumn{3}{|c|}{ FASE BAJISTA DEL CICLO CREDITICIO } \\
\hline & $\begin{array}{c}\text { Septiembre } \\
1997 \\
\text { Mill. Euros }\end{array}$ & $\begin{array}{l}\text { Diciembre } \\
2007 \\
\text { Mill. Euros }\end{array}$ & $\begin{array}{c}\text { Var. Media } \\
\text { Anual Periodo } \\
(\%)\end{array}$ & $\begin{array}{l}\text { Junio } \\
2009 \\
\text { Mill. Euros }\end{array}$ & $\begin{array}{l}\text { Marzo } \\
2012 \\
\text { Mill. Euros }\end{array}$ & $\begin{array}{c}\text { Var. Media } \\
\text { Anual Periodo } \\
(\%)\end{array}$ \\
\hline Crédito a Actividades Productivas & 191,414 & 943,087 & 16,6 & 1.007 .492 & 935,176 & $-2,0$ \\
\hline Agricultura, ganadería y pesca & 9,494 & 25,245 & 10,2 & 23,732 & 21,416 & $-5,1$ \\
\hline Industria (excepto construc.) & 55,686 & 141,571 & 9,5 & 158,800 & 139,850 & $-2,3$ \\
\hline Construcción & 25,065 & 153,453 & 18,8 & 134,690 & 96,193 & $-12,8$ \\
\hline Servicios Inmobiliarios & 16,041 & 303,514 & 33,2 & 324,663 & 295,696 & $-1,7$ \\
\hline Servicios No Inmobiliarios & 85,128 & 319,304 & 13,5 & 365,607 & 382,020 & 2,1 \\
\hline Crédito a Personas Físicas & 138,175 & 789,250 & 18,8 & 815,068 & 782,441 & $-0,9$ \\
\hline Adquisición y rehabilitación vivienda & 98,229 & 623,540 & 20,2 & 651,566 & 649,602 & 0,2 \\
\hline Bienes de Consumo Duradero & 15,296 & 56,576 & 14,1 & 49,583 & 35,835 & $-11,2$ \\
\hline Resto & 24,650 & 109,133 & 15,5 & 113,922 & 97,004 & $-2,8$ \\
\hline Crédito a Inst. Privadas sin Fines Lucro & 867 & 6,089 & 19,7 & 5,382 & 6,643 & 4,4 \\
\hline Crédito Sin Clasificar & 9,790 & 21,788 & 8,8 & 33,063 & 44,193 & 20,2 \\
\hline Total Crédito & 340,248 & 1.760 .213 & 17,3 & 1.861 .005 & 1.768 .454 & $-1,2$ \\
\hline $\begin{array}{l}\text { Pro memoria: } \\
\text { Construcción y vivienda }\end{array}$ & 139,335 & 1.080 .507 & 22,2 & 1.110 .917 & 1.041 .492 & $-1,9$ \\
\hline
\end{tabular}

Fuente: Elaboración propia a partir de Banco de España

El resto de sectores productivos registraron crecimientos del crédito mucho más moderados. Así, el concedido a los servicios no inmobiliarios aumentó a una tasa media anual del 13,5\%; el destinado a la agricultura, ganadería y pesca creció al 10,2\%; y el dirigido a la industria (excluida la construcción) experimentó un aumento medio anual del 9,5\%. Este crecimiento diferenciado entre el crédito concedido a los sectores de la construcción y a los servicios inmobiliarios respecto al del resto de sectores productivos hizo que el peso de la financiación otorgada a la construcción (entendida en sentido amplio) sobre el total del crédito destinado a financiar actividades productivas aumentara rápidamente, pasando de representar el 21,5\% en septiembre de 1997 al 48,5\% diez años más tarde.

REVESCO No 109 - MONOGRÁFICO: La financiación complementaria y la respuesta de la economía social: la situación del "des-crédito" bajo la crisis financiera -

ISSN: 1885-8031 - www.ucm.es/info/revesco 
Por su parte, el concedido a personas físicas registró en ese período un crecimiento medio anual del $18,8 \%$. Al igual que ocurriera con el crédito a las actividades productivas, dentro de una tónica general de elevado aumento del crédito concedido a los distintos tipos de gasto, un especial crecimiento registró el destinado a la adquisición y rehabilitación de vivienda, que experimentó un aumento medio anual del 20,2\%, frente al 14,1\% del concedido para la adquisición de bienes de consumo duradero y del $15,5 \%$ del resto de crédito a personas físicas.

Gráfico 4. Crédito de las entidades de crédito residentes a otros sectores residentes según finalidades

Tasas de Variación Interanual

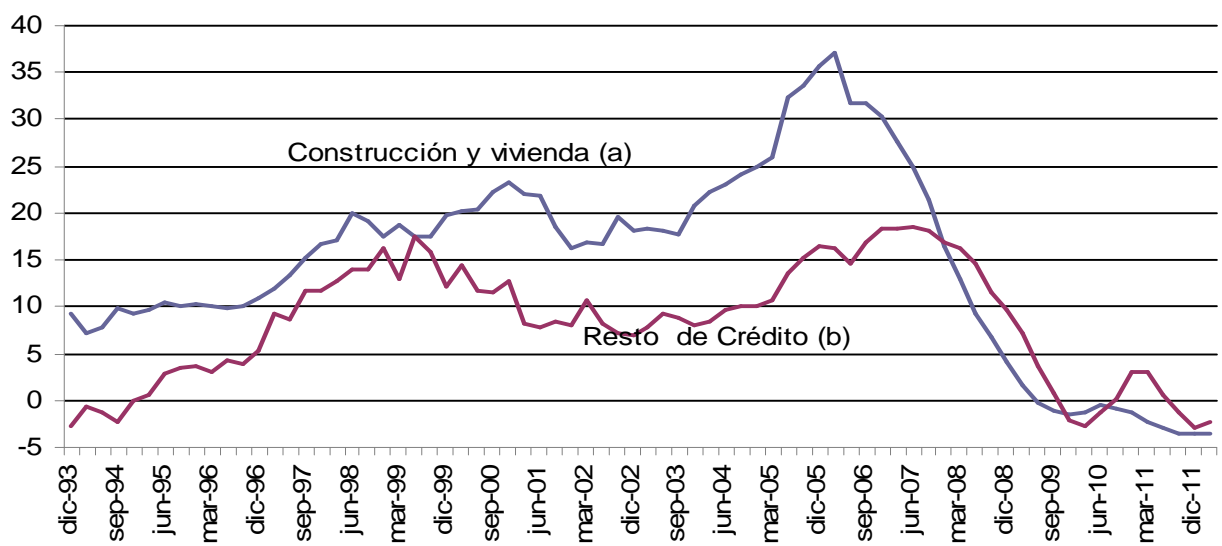

(a) Comprende: construcción, servicios inmobiliarios y adquisición y rehabilitación de viviendas.

(b) Comprende: agricultura, ganadería y pesca, servicios no inmobiliarios, industria y el crédito concedido a las personas físicas distinto del destinado a adquisición y rehabilitación de vivienda.

Fuente: Elaboración propia a partir de Banco de España

Por último, si, por un lado, agrupamos el crédito concedido a construcción, actividades inmobiliarias y adquisición y rehabilitación de viviendas y, por otro, el concedido al resto de actividades productivas (industria, servicios no inmobiliarios y agricultura y pesca) y el otorgado a las personas físicas no destinado a la adquisición y rehabilitación de viviendas, obtenemos una visión más precisa aún del comportamiento diferencial del crédito concedido a vivienda y construcción y el resto del crédito, resultando que el primero aumentó a una tasa de crecimiento medio anual del 22,2\%, y el segundo lo hizo al 12,4\% (véase el Gráfico 4).

REVESCO No 109 - MONOGRÁFICO: La financiación complementaria y la respuesta de la economía social: la situación del "des-crédito" bajo la crisis financiera -

ISSN: 1885-8031 - www.ucm.es/info/revesco 
Este desbordado crecimiento del crédito hipotecario en sentido amplio hizo que pasara de representar el $41,1 \%$ del total de crédito destinado a financiar actividades productivas y a personas físicas a inicios de la fase expansiva del ciclo crediticio, al 62\% a finales de 2007 (véase el Gráfico 5).

Gráfico 5. Crédito concedido a construcción y vivienda sobre el total del crédito a actividades productivas y personas físicas (a)

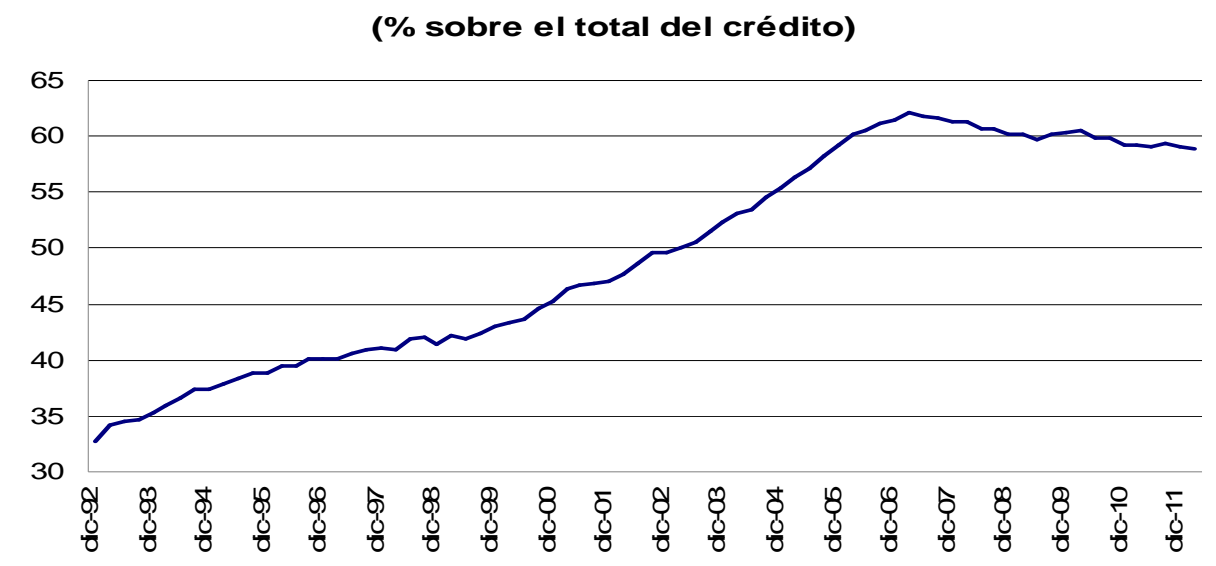

(a) Comprende: construcción, servicios inmobiliarios y adquisición y rehabilitación de viviendas.

Fuente: Elaboración propia a partir de Banco de España

\section{LOS EXCESOS DE LA FASE EXPANSIVA DEL CICLO CREDITICIO Y LOS DESEQUILIBRIOS ACUMULADOS}

El hecho de que en la economía española desde mediados de la última década del pasado siglo hasta el inicio de la crisis financiera global se produjera un elevado crecimiento del crédito es algo lógico y racional si tenemos en cuenta la fuerte expansión que en el citado periodo experimentó el PIB. No obstante, tal y como se puede observar en el Gráfico 6, la expansión de la actividad económica no justifica la intensidad en el crecimiento en el crédito al sector privado que se produjo desde el inicio de 2003 hasta finales de 2007, por lo que podemos afirmar que en el citado período se registró un autentico "boom crediticio", el cual estuvo asociado con la acumulación de desequilibrios en el conjunto de la economía española y en las propias entidades de crédito.

REVESCO No 109 - MONOGRÁFICO: La financiación complementaria y la respuesta de la economía social: la situación del "des-crédito" bajo la crisis financiera -

ISSN: 1885-8031 - www.ucm.es/info/revesco 
En efecto, con una perspectiva de varias décadas, podemos observar en este Gráfico 6 la estrecha relación general entre el crecimiento del PIB real y el del crédito al sector privado no financiero en España. Sin embargo, aproximadamente entre 2003 y 2008 la coincidencia entre el ciclo económico y el ciclo crediticio se rompen completamente, observándose una expansión crediticia mucho más acusada que la experimentada en la actividad real.

Este crecimiento del crédito tan importante generó varios efectos distintos, pero interrelacionados, que se ponen de manifiesto en los Gráficos 7 al 10:

Gráfico 6. PIB y crédito al sector privado no financiero

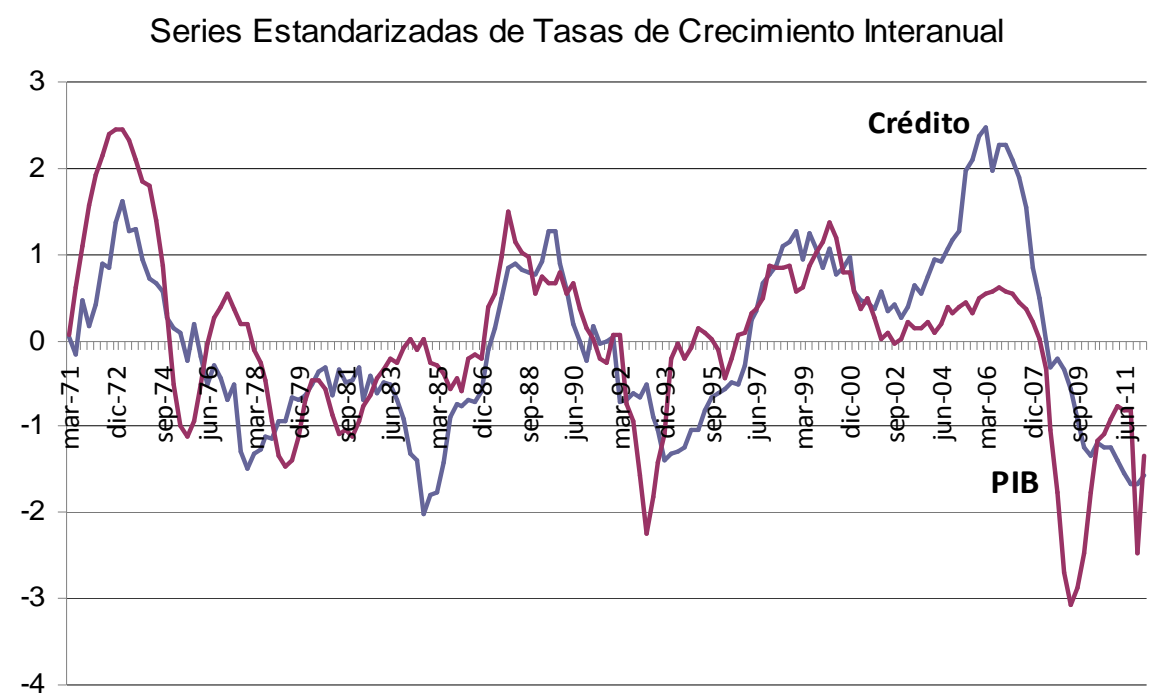

Fuente: Elaboración propia a partir de Banco de España

- En primer lugar, un aumento espectacular de la financiación recibida, vía créditos, por el sector privado no financiero (Gráfico 7). En efecto, este crédito llegó a superar el 175\% del PIB español en algunos trimestres de 2009 y 2010, disminuyendo a partir de entonces, si bien todavía alcanza niveles muy elevados, pues supera actualmente el $150 \%$ de nuestro PIB. Además, esta situación del crédito contrasta con la existente alrededor de quince años atrás, en la que ese crédito significaba entre el $60 \%$ y el $70 \%$ de nuestra producción.

- En segundo, la gran relevancia del endeudamiento crediticio de este sector en comparación con el de otros países de nuestro entorno económico. En efecto, salvo

REVESCO No 109 - MONOGRÁFICO: La financiación complementaria y la respuesta de la economía social: la situación del "des-crédito" bajo la crisis financiera -

ISSN: 1885-8031 - www.ucm.es/info/revesco 
Irlanda, España es el país en el que el sector privado alcanza el mayor nivel de endeudamiento crediticio, superando en casi 25 puntos al que le sigue, que es el portugués. Resulta además destacable el hecho de que los tres países con mayor endeudamiento crediticio del sector privado no financiero que aparecen en el Gráfico 8, son algunos de los que mayores dificultades están teniendo en la actual situación de crisis económica y financiera global.

- En tercero, si tenemos en cuenta, además de la financiación mediante créditos, la obtenida a través de emisiones de valores (Gráfico 9), lo cual resulta otra forma de financiación del sector de sociedades no financieras, y lo comparamos con la conseguida exclusivamente a través de créditos, podemos comprobar que también se ha producido un crecimiento significativo de la financiación del sector privado a través de títulos, pues mientras que en 1995, el endeudamiento de este sector equivalía al 80\% del PIB español, con casi 15 puntos correspondientes al endeudamiento a través de valores, a finales de 2010, suponía prácticamente el $230 \%$ de nuestra producción, cuando la correspondiente al crédito era del 160\%. Así pues, en 2010, el endeudamiento a través de la emisión de valores era del $70 \%$ aproximadamente del PIB español, más de 50 puntos que el de quince años antes.

Gráfico 7. Crédito al sector privado no financiero (\% del pib)

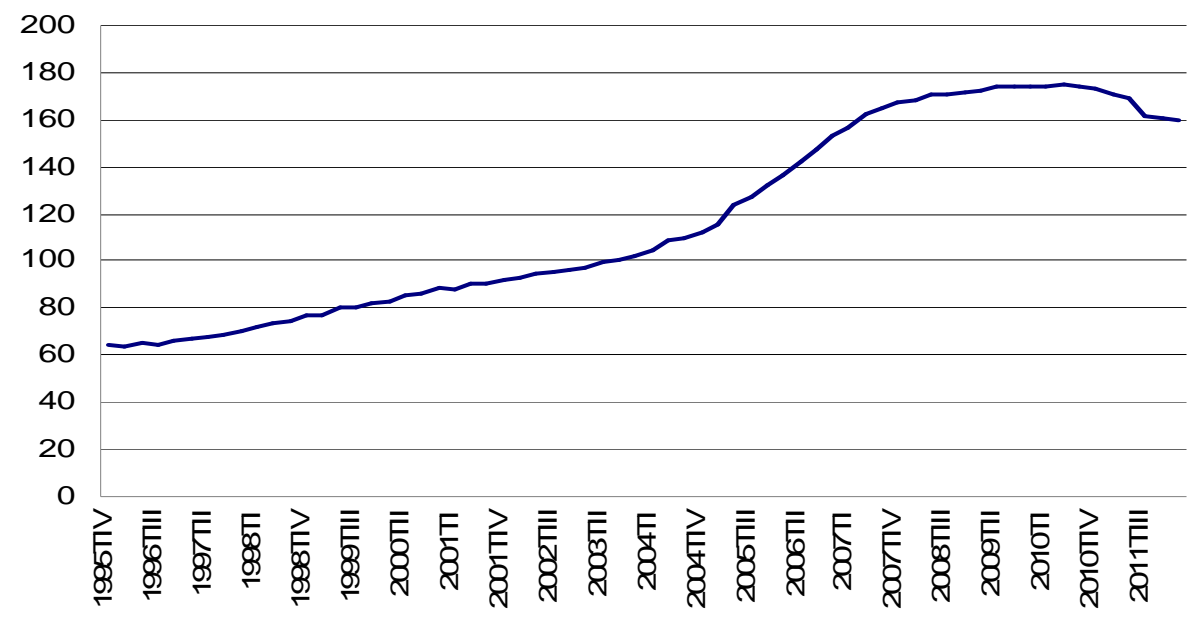

Fuente: Elaboración propia a partir de Banco de España

REVESCO No 109 - MONOGRÁFICO: La financiación complementaria y la respuesta de la economía social: la situación del "des-crédito" bajo la crisis financiera -

ISSN: 1885-8031 - www.ucm.es/info/revesco 
Gráfico 8. Crédito al sector privado no financiero (\% del pib)

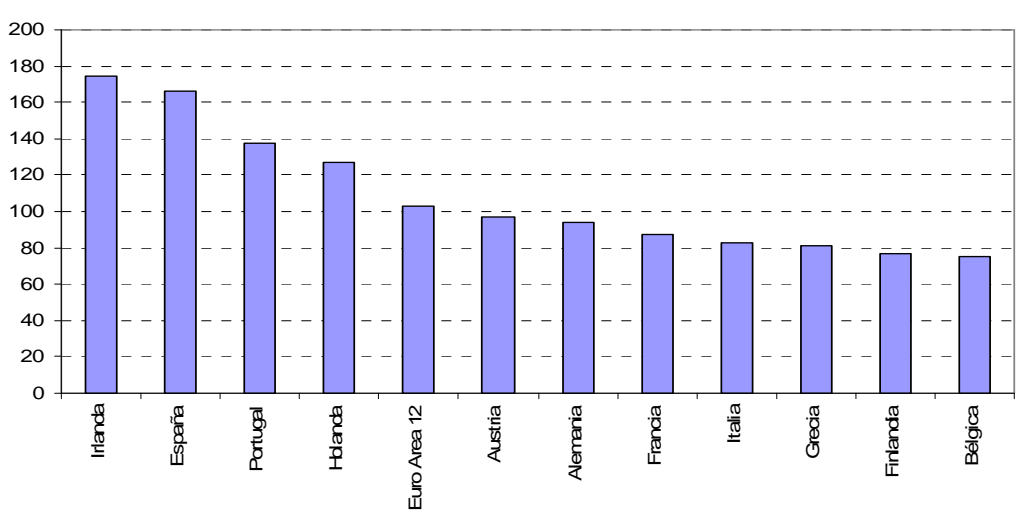

Fuente: Elaboración propia a partir de EUROSTAT

- Finalmente, este excesivo endeudamiento del sector privado no se ha financiado mediante el ahorro nacional, canalizado a través de las instituciones financieras, sino que éstas, para atender a la demanda creciente de financiación, han tenido que acumular niveles de deuda muy elevados, que han venido creciendo de forma ininterrumpida desde prácticamente los primeros años del nuevo siglo (Gráfico 10). En efecto, como podemos comprobar en el gráfico, mientras que durante los años noventa el nivel de endeudamiento en relación al PIB del sector de instituciones financieras se mantuvo bastante estable entre el 10\% y el 20\%, a partir de 2003 inicia una escalada, que lo sitúa en el momento del inicio de la crisis, en 2007, cerca del valor de nuestra producción, manteniéndose estable en 2008, para volver a crecer en 2009 (hasta el 110\%), que es el nivel de endeudamiento actual.

REVESCO No 109 - MONOGRÁFICO: La financiación complementaria y la respuesta de la economía social: la situación del "des-crédito" bajo la crisis financiera -

ISSN: 1885-8031 - www.ucm.es/info/revesco 
Gráfico 9. Endeudamiento del sector privado no financiero (1) (\% del pib)

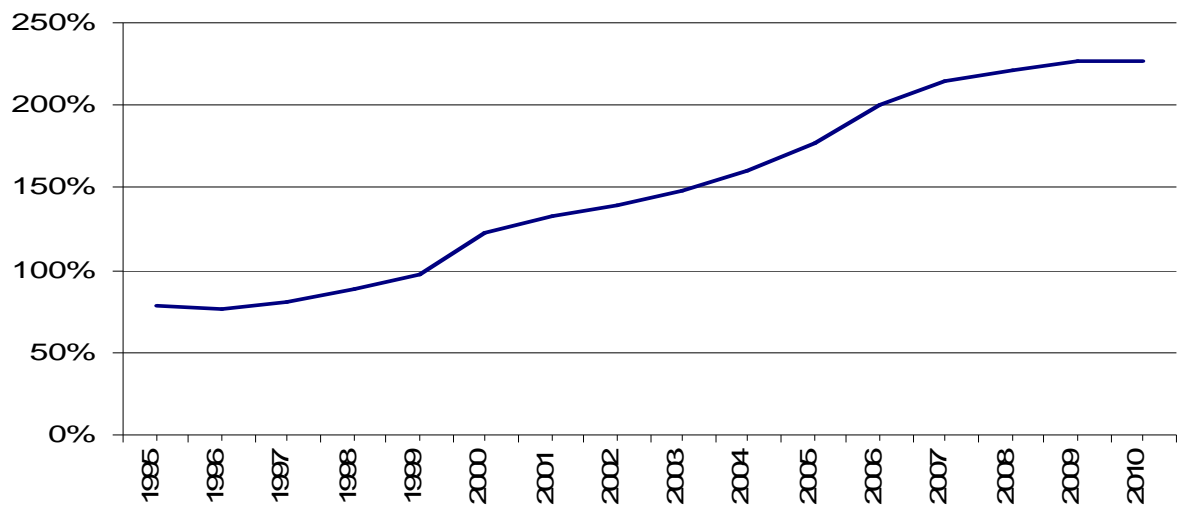

1) Entendido como suma de Préstamos y Valores distintos de acciones

Fuente: Elaboración propia a partir de Banco de España

Gráfico 10. Endeudamiento de las instituciones financieras (1) (\% del pib)

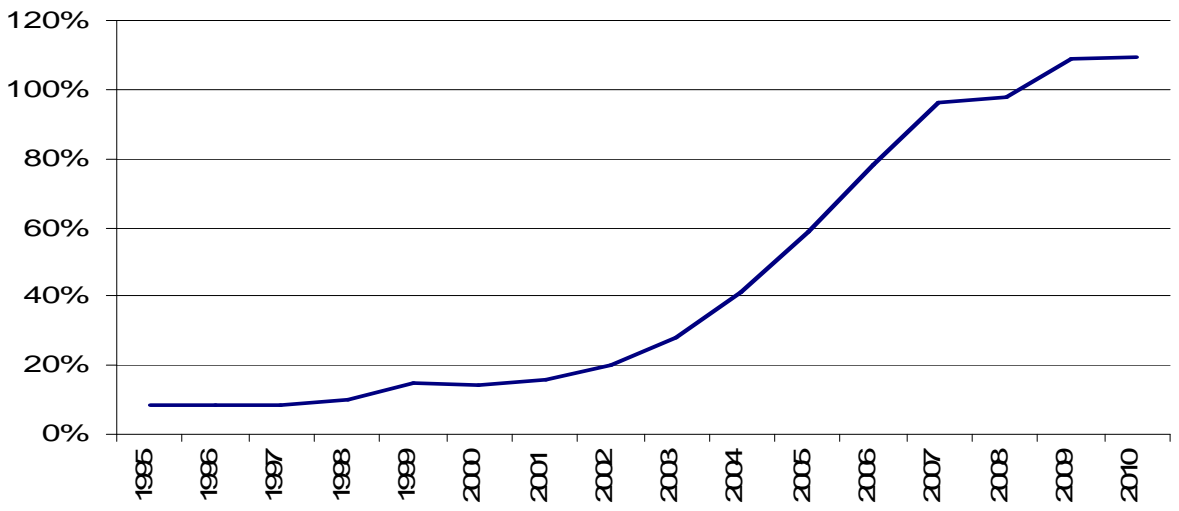

(1) Entendido como suma de Préstamos y Valores distintos de acciones

Fuente: Elaboración propia a partir de Banco de España

\section{LA PROFUNDA FASE BAJISTA DEL CICLO CREDITICIO DE LA ECONOMÍA ESPAÑOLA}

Al igual que la fase expansiva del último ciclo crediticio se caracterizó por su intensidad y duración, la fase bajista en la que actualmente se encuentra inmersa la economía española muy probablemente va a tener las mismas características.

REVESCO No 109 - MONOGRÁFICO: La financiación complementaria y la respuesta de la economía social: la situación del "des-crédito" bajo la crisis financiera -

ISSN: 1885-8031 - www.ucm.es/info/revesco 
La intensidad de la restricción crediticia y la rapidez con que ésta se ha producido, la comprobamos al analizar la evolución registrada por el crédito al sector privado desde finales de 2006 a mediados de 2009. En noviembre de 2006, el crédito concedido por las entidades de crédito a familias y empresas no financieras se encontraba en el momento álgido de su etapa expansiva, con un crecimiento interanual del 24,6\%. A partir de ese momento se inició una ligera desaceleración, de tal forma que cuando se inicia la crisis financiera global, en septiembre de 2007, seguía creciendo al 21,2\%, momento a partir del cual la desaceleración es mucho más acusada, hasta que en julio de 2009, por primera vez en las últimas cuatro décadas, el crédito bancario al sector privado no financiero registró una tasa de variación nominal interanual negativa (véase de nuevo el Gráfico 1). Por tanto, en menos de tres años el crédito al sector privado pasó de crecer en torno al $25 \%$, en términos nominales, a decrecer.

Si utilizamos los criterios establecidos en el apartado 2 para identificar las distintas fases de los ciclos crediticios, la actual fase bajista se inició en junio de 2009, por lo que ya han transcurrido más de tres años sin que hasta la fecha exista ningún elemento que nos permita vislumbrar su conclusión. Si tenemos en cuenta que según la evidencia empírica las fases bajistas del ciclo crediticio de las economías avanzadas tienen una duración media inferior a los dos años, comprobamos la prolongada duración de la actual restricción crediticia por la que atraviesa la economía española. Durante este período, el crédito al sector privado financiero ha descendido a una media anual del 1,2\%, en términos nominales, y del $3 \%$, en términos reales, y lo que es más grave, con una tendencia de prácticamente continuado deterioro, y que culminó en el último trimestre de 2011, en el que la tasa real de variación del crédito fue del $-5,7 \%$.

El impacto de la fase bajista del ciclo crediticio se ha dejado sentir tanto en el crédito concedido a familias como en el que se dirige a las empresas no financieras. No obstante, son estas últimas las que se están enfrentando a una mayor restricción financiera; pues, el descenso medio anual del crédito concedido por las entidades de crédito a éstas ha sido del $4 \%$, frente al 1,4\% del concedido a las familias (véase el Gráfico 11).

Si se analiza el comportamiento del crédito concedido a otros sectores residentes, distinguiendo entre sus diferentes finalidades, durante la actual fase bajista del ciclo crediticio (véase de nuevo el cuadro 1), se observa como el destinado a actividades productivas está REVESCO No 109 - MONOGRÁFICO: La financiación complementaria y la respuesta de la economía social: la situación del "des-crédito" bajo la crisis financiera -

ISSN: 1885-8031 - www.ucm.es/info/revesco 
reduciéndose a una tasa mayor que la que registra el concedido a personas físicas, $-2,0$ y $-0,9$, respectivamente.

Dentro de este ciclo, se comprueba un descenso generalizado del crédito concedido a todos los sectores productivos, con la excepción del destinado a los servicios no inmobiliarios que ha seguido aumentando a una tasa media anual del 2,1\%.

Por su parte, el sector de la construcción es que el que está experimentado un mayor descenso (-12,8\% en tasa media anual), mientras que, por el contrario, los servicios inmobiliarios, aunque registran una tasa de variación negativa, ésta es inferior a la caída que registra la financiación concedida al conjunto de actividades productivas. No obstante, hay que resaltar que desde inicios de 2011 se ha producido un aumento en el ritmo de descenso del crédito concedido a los servicios inmobiliarios, de tal forma que, en la primera mitad de 2012, descienden a una tasa interanual superior al $5 \%$.

Gráfico 11. Préstamos de las entidades de crédito residentes al sector privado no financiero

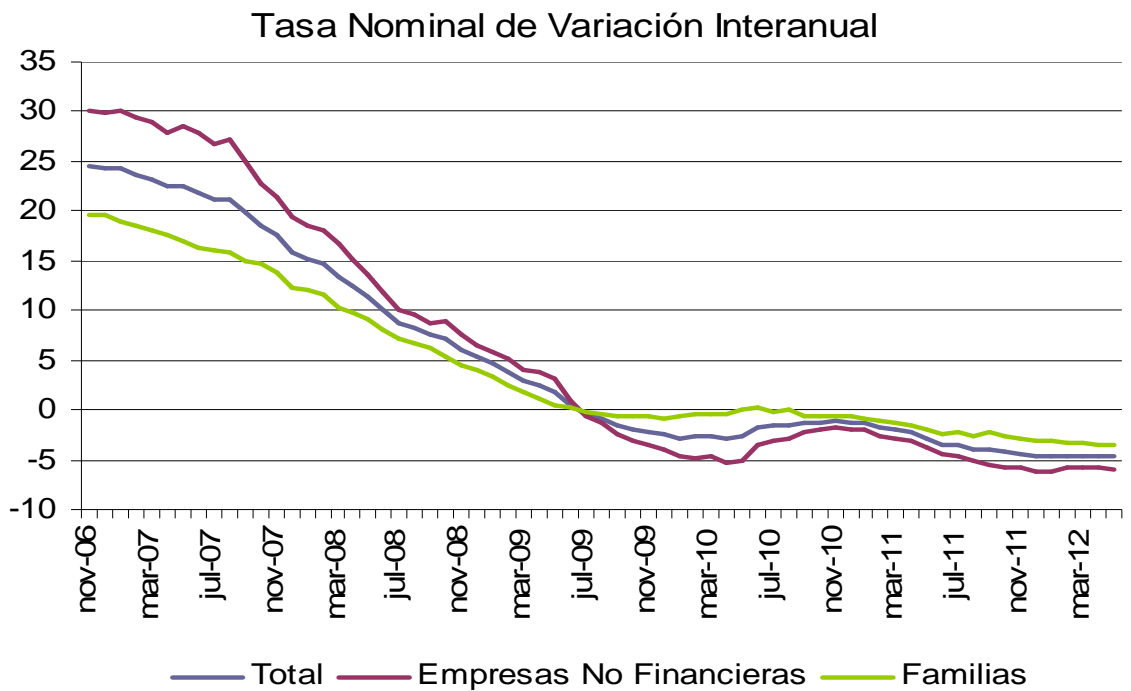

Fuente: Elaboración propia a partir de Banco de España

Dentro del crédito concedido a personas físicas hay que diferenciar el comportamiento, por un lado, del destinado a la adquisición y rehabilitación de viviendas, y, por otro, el que se dirige a la compra de bienes de consumo duradero. El stock crediticio dirigido a financiar la compra y rehabilitación de vivienda prácticamente se ha mantenido

REVESCO No 109 - MONOGRÁFICO: La financiación complementaria y la respuesta de la economía social: la situación del "des-crédito" bajo la crisis financiera -

ISSN: 1885-8031 - www.ucm.es/info/revesco 
constante, evidenciando la restricción actualmente existente para la concesión de nuevas hipotecas unido a la pervivencia de la mayor parte de las hipotecas existentes como consecuencia de sus largos períodos de amortización. Por el contrario, el crédito concedido para adquisición de bienes de consumo duradero se ha visto fuertemente afectado, descendiendo durante esta fase bajista del ciclo a una tasa media anual del 11,2\%.

Si comparamos, por último, el comportamiento durante la fase bajista del ciclo crediticio de la financiación concedida a la construcción en sentido amplio, es decir, construcción, actividades inmobiliarias y adquisición y rehabilitación de viviendas, y el resto del crédito concedido, comprobamos un descenso medio anual del primero del 1,9\% frente al $0,1 \%$ del resto del crédito. No obstante, esta mayor caída del crédito destinado a construcción y vivienda no ha supuesto una corrección importante en su desmesurado peso sobre el total del crédito, y así, en el primer trimestre de 2012, seguía representando un 58,9\% del mismo.

\section{6. ¿HAN CONTRIBUIDO LAS ENTIDADES BANCARIAS DE CARÁCTER SOCIAL AL ÚLTIMO CICLO CREDITICIO?}

Hasta ahora nos hemos referido en los datos analizados al papel de las entidades de crédito en conjunto en la generación de los ciclos crediticios de la economía española, sin distinguir entre las diferentes instituciones que integran esta categoría. Sin embargo, en este apartado, vamos a separar los tres grandes grupos de entidades de depósito, bancos, cajas de ahorros y cooperativas de crédito, de las que las dos últimos integran lo que se denomina habitualmente las entidades bancarias de carácter social.

Como es sabido, el sector bancario español está conociendo un proceso de reestructuración muy intenso ${ }^{6}$, sobre todo en los grupos institucionales de carácter social, con la realización de fusiones, ya sean tradicionales o las denominadas "frías" (sistemas institucionales de protección), o su conversión en bancos (en el caso de las cajas de ahorros),

\footnotetext{
${ }^{6}$ Desde hace ya muchos meses, nuestras autoridades económicas han aprobado normas que han ido alentando este proceso de fusiones o de conversiones en bancos, sobre todo para aquellas entidades que han estado, y están, más afectadas por la crisis financiera. Pueden consultarse, entre otros, el Real Decreto-Ley 9/2009, que crea el Fondo de Reestructuración Ordenada Bancaria; el Real Decreto-Ley 11/2010, de 9 de julio, que reforma el régimen jurídico de las cajas de ahorros; el Real Decreto-Ley 2/2011, del 18 de febrero, que refuerza los recursos propios de las entidades de crédito; el Real Decreto-Ley 2/2012, de saneamiento del sector financiero español,; el Real Decreto-Ley 18/2012, de 11 de mayo, sobre saneamiento y venta de activos inmobiliarios del sector financiero; y el Real Decreto-Ley 24/2012, de 31 de agosto, de reestructuración y resolución de entidades de crédito.
}

REVESCO No 109 - MONOGRÁFICO: La financiación complementaria y la respuesta de la economía social: la situación del "des-crédito" bajo la crisis financiera -

ISSN: 1885-8031 - www.ucm.es/info/revesco 
hasta el punto de que el sector de cajas prácticamente ha desaparecido en nuestro país en los últimos años y el de cooperativas ha conocido una profunda reestructuración ${ }^{7}$.

Fruto de ello, el Banco de España, a través de sus Boletines Estadísticos, no ofrece información desagregada de la actividad crediticia de los diferentes grupos de entidades de depósito desde los primeros meses del año 2011. Por tanto, para analizar la importancia de las entidades bancarias de carácter social en este ciclo crediticio, vamos a recoger los principales datos disponibles hasta finales de 2010.

Así, en primer término, en el Gráfico 12 recogemos la evolución de los créditos destinados en nuestro país para la financiación de actividades productivas, desde 2000 hasta 2010, así como una comparación en tres momentos de ese período de la participación de cada uno de los grupos que componen las entidades de depósito; en concreto, al principio y al final del período y prácticamente en el momento del inicio de la crisis económica y financiera.

Gráfico 12. Evolución y comparativa del crédito concedido por las entidades de depósito para la financiación de actividades productivas

MILLONES DE EUROS

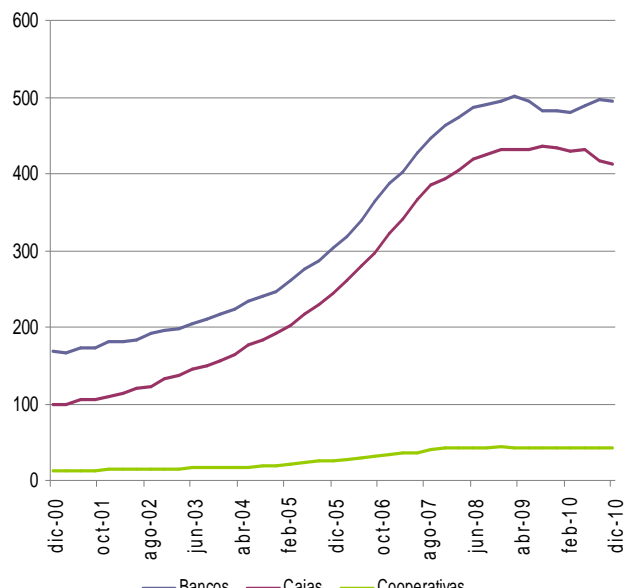

PARTICIPACIÓN DE CADA GRUPO

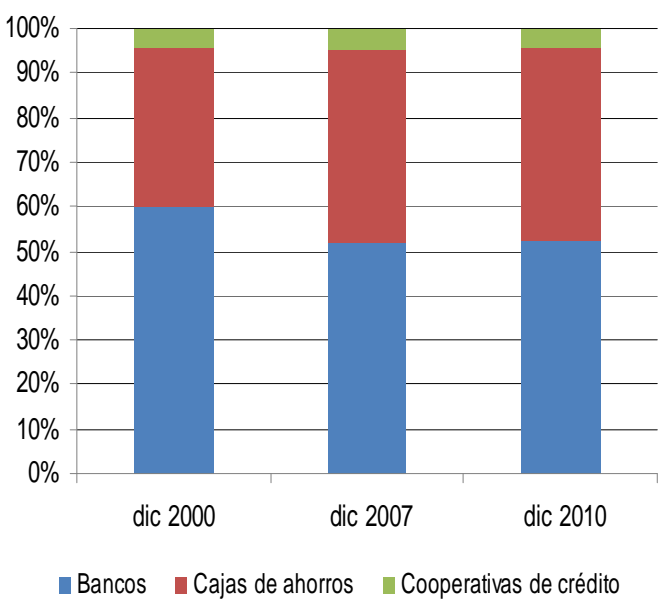

Fuente: Banco de España

\footnotetext{
${ }^{7}$ En la práctica, sólo quedan dos cajas de ahorros tradicionales, de tamaño además reducido (Pollensa y Ontinyent). Por su parte, en el sector de las cooperativas de crédito se han desarrollado fusiones y sistemas institucionales de protección, constituyéndose cinco grandes grupos (Cajas Rurales Unidas, formadas por los SIP de Cajamar y de Cajas Rurales del Mediterráneo, Solventia, Grupo Ibérico, Globalcaja y Nueva Caja Rural de Aragón). Para un mayor detalle sobre este proceso, véase A. Calvo, R. Palomo y M. Gutiérrez (2012).
}

REVESCO No 109 - MONOGRÁFICO: La financiación complementaria y la respuesta de la economía social: la situación del "des-crédito" bajo la crisis financiera -

ISSN: 1885-8031 - www.ucm.es/info/revesco 
En el gráfico de la izquierda podemos comprobar que la evolución del crédito destinado a financiar actividades productivas, en lo que llevamos de siglo, ha respondido a una contribución de todos los grupos institucionales, en mayor medida de los bancos y de las cajas de ahorros. Ese crédito ha crecido de forma continuada hasta finales de 2008, si bien en menor medida este último año, habiendo pasado en la banca desde casi 170 mil millones de euros a una cifra próxima al medio billón, mientras que en las cajas de 100 mil millones se situó a finales de 2008 en 432 mil. A partir de entonces, esa cifra se ha ido reduciendo en las cajas prácticamente todos los trimestres, lo que refleja la crisis en la que empezaba a sumirse el sector, mientras que en la banca, tras un descenso acusado durante 2009, se estabiliza a partir de entonces. Por su parte, las cooperativas de crédito, con cifras más modestas han seguido una tendencia similar, es decir un aumento importante hasta el inicio de la crisis (de casi 3,5 veces hasta finales de 2008), y una estabilización del crédito para financiar actividades productivas en los últimos trimestres.

Por otro lado, si nos fijamos en la participación de cada grupo institucional en este crédito, mientras que las cooperativas han mantenido en todo el período una situación estable (entre el 4,3\% y el 4,6\%), las cajas de ahorros ganaron una cuota significativa sobre la banca, pues, a finales de 2000, estas entidades participaban en el $35,4 \%$ del total $(60,3 \%$ de la banca), mientras que, a finales de 2007, se situaban en el 43,9\% (frente al 51,5\%), cuotas que se mantuvieron muy próximas a finales de 2010.

Si aproximamos más el crédito al sector industrial y al de la construcción, los resultados también resultan significativos, como podemos comprobar en el Gráfico 13.

REVESCO No 109 - MONOGRÁFICO: La financiación complementaria y la respuesta de la economía social: la situación del "des-crédito" bajo la crisis financiera -

ISSN: 1885-8031 - www.ucm.es/info/revesco 
Gráfico 13. Evolución y comparativa del crédito concedido por las entidades de depósito para la industria y la construcción
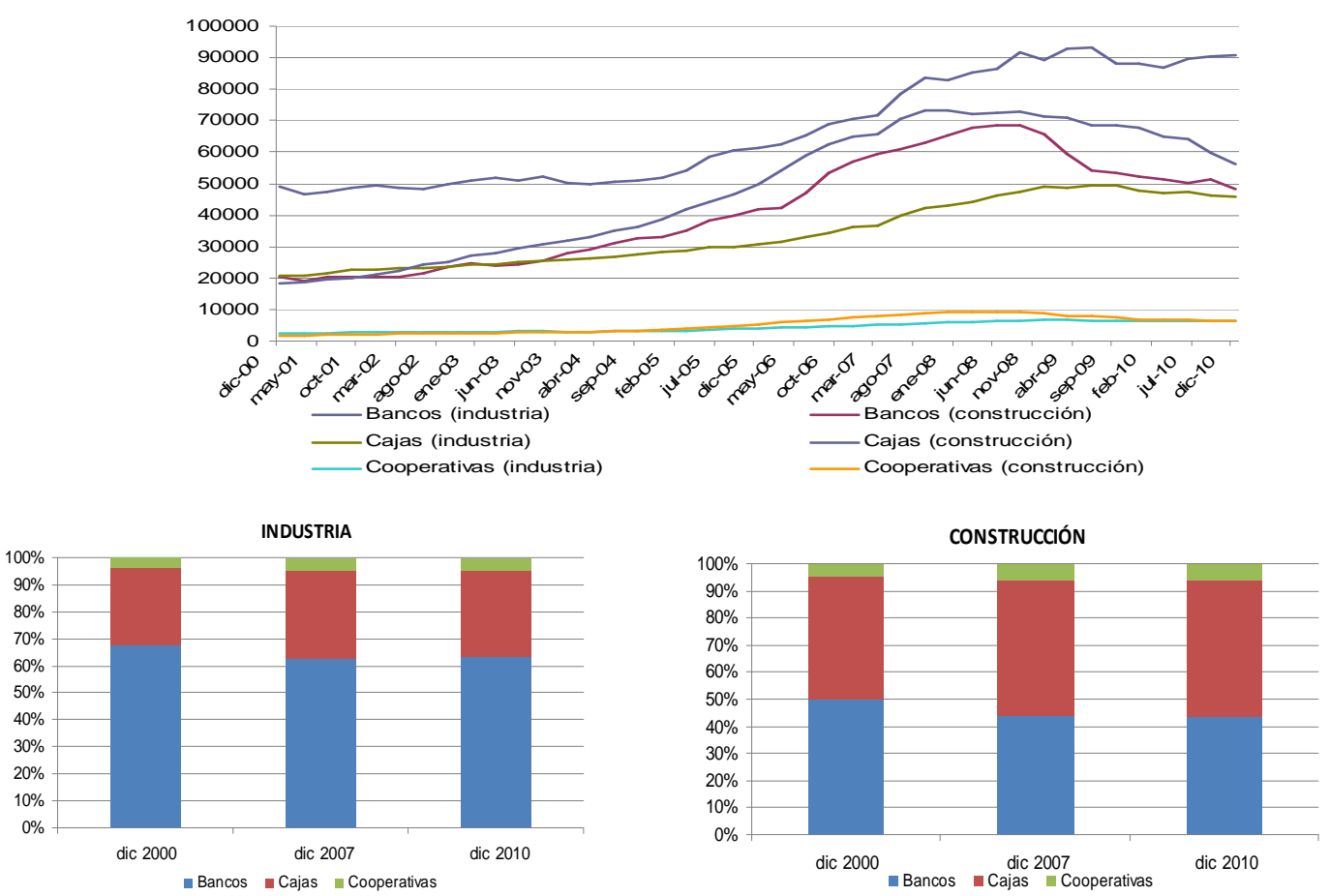

Fuente: Banco de España.

De su contenido destaca la mayor relevancia de la banca en el crédito industrial y de las cajas de ahorros en el de la construcción. Ahora bien, el crecimiento de este último tipo de crédito ha sido significativo antes de la crisis en los tres grupos institucionales, fundamentalmente en el sector de las cajas de ahorros, pues incluso a principios del período los bancos concedían un mayor volumen de este tipo de créditos. Además, la crisis le ha afectado en mayor medida, cayendo los concedidos, incluso de forma importante, sobre todo desde 2008, aunque en las cajas el deterioro del crédito también ha sido patente en el industrial, el cual en cambio se ha mostrado con un cierto estancamiento en los bancos y en las cooperativas.

Ello ha supuesto, como se observa en los gráficos de participación, que antes de la crisis, las cajas de ahorros ganaron cuota de mercado a los bancos, en uno y otro tipo de créditos, haciéndolo más modestamente las cooperativas.

REVESCO No 109 - MONOGRÁFICO: La financiación complementaria y la respuesta de la economía social: la situación del "des-crédito" bajo la crisis financiera -

ISSN: 1885-8031 - www.ucm.es/info/revesco 
Por tanto, la distinción entre grupos institucionales de entidades de depósito pone de manifiesto la contribución de las entidades bancarias de carácter social en los ciclos crediticios observados en los últimos años en la economía española, siendo además un protagonista destacado el sector de las cajas de ahorros, el cual consiguió mejorar su cuota de mercado en todo tipo de créditos, siendo en cambio el más afectado por la crisis que posteriormente se desencadenó.

\section{LA CONTRACCIÓN DEL CRÉDITO: ¿CAÍdA EN LA DEMANDA? O} ¿RESTRICCIÓN DE LA OFERTA?

La contracción del crédito al sector privado en un momento de recesión económica, como el que atraviesa la economía española, no es algo sorprendente, dado que, como ya señalamos, es conocida la existencia de una fuerte interrelación entre la actividad económica y el crédito al sector privado, hasta el punto de poder afirmar que el ciclo económico va acompañado de un ciclo de crédito. Sin embargo, lo que no resulta sencillo es determinar la naturaleza de las relaciones que se establecen entre ambos, así como cuál es su relación de causalidad. En concreto, en una época de fuerte recesión económica como la actual: ¿la contracción del crédito se debe a la inexistencia de demanda crediticia?, en cuyo caso la causalidad se establecería desde la actividad económica hacia el crédito, o, por el contrario ¿la caída en la actividad económica está relacionada con la contracción del crédito?, en cuyo caso la causalidad se establecería desde el crédito hacia la actividad económica. La literatura económica no es concluyente al respecto, existiendo tanto teorías que enfatizan el papel de la demanda crediticia a la hora de explicar el comportamiento del crédito, como otras que asignan un mayor peso al lado de su oferta ${ }^{8}$.

Así pues, la fuerte contracción del crédito en España puede ser el resultado de la reducción de la oferta por parte de las entidades financieras, o de la demanda efectuada por las sociedades no financieras y por los hogares, o de una combinación de ambas. Dicho en otras palabras, la reducción en nuestro país del crédito al sector privado puede ser consecuencia de una menor disposición de las entidades financieras residentes a conceder préstamos al sector

\footnotetext{
${ }^{8}$ Véase BCE (2011) para un análisis de los factores de oferta y de demanda que influyen en la evolución del crédito.
}

REVESCO No 109 - MONOGRÁFICO: La financiación complementaria y la respuesta de la economía social: la situación del "des-crédito" bajo la crisis financiera -

ISSN: 1885-8031 - www.ucm.es/info/revesco 
privado o de que el sector privado demande menos crédito como consecuencia de la caída en la actividad económica y el deterioro en sus expectativas de rentas futuras, o de una combinación de ambas.

El predominio de los factores de oferta o de demanda de crédito como determinantes de la contracción crediticia cobra para nuestras autoridades económicas una especial relevancia en el momento presente. En efecto, se debe tener en cuenta que si su contracción fuera fundamentalmente el resultado de una menor demanda crediticia asociada a la recesión económica, las dificultades para obtener financiación no serían un obstáculo para una recuperación futura de la actividad económica. Por el contrario, si la caída en la actividad crediticia fuera resultado de una restricción por el lado de la oferta, el retorno de la disposición de las entidades financieras a conceder créditos constituiría un elemento fundamental para la reactivación de la economía española, y para ello una resolución rápida y exitosa de la crisis bancaria sería un elemento imprescindible 9 .

En la información tradicional disponible, las cifras, que además son las que hemos utilizado hasta ahora, corresponden al volumen de créditos realmente concedidos, y por tanto, son el resultado de la aceptación por las entidades financieras, a partir de una demanda del mismo desconocida, de un número mayor o menor de solicitudes. Sin embargo, los volúmenes manejados no reflejan adecuadamente los posibles cambios en la demanda por parte del sector privado no financiero. Para tratar de conseguir una información más precisa en este ámbito, que nos permita aproximar una respuesta a la cuestión suscitada en el propio título de este epígrafe, y así ver las posibilidades de una pronta recuperación del crédito, vamos a analizar los resultados obtenidos y publicados periódicamente por el Banco de España en su Encuesta de Préstamos Bancarios ${ }^{10}$ y los alcanzados por el Consejo Superior de Cámaras a partir de sus encuestas trimestrales.

En el Gráfico 14 recogemos de la Encuesta de Préstamos Bancarios precisamente la variación de los criterios de aprobación de los mismos ${ }^{11}$, correspondientes a los créditos a

\footnotetext{
${ }^{9}$ Para un análisis de las dificultades existentes para lograr una reactivación económica sin la recuperación del crecimiento del crédito, véase Claessens et al. (2009).

${ }^{10}$ Para conocer esos resultados se puede acudir directamente a las publicaciones periódicas del Banco de España. Véase, no obstante, con más detalle M. Mulino (2012) y Banco de España (2009).

${ }^{11}$ En esta encuesta participan diez instituciones españolas de las más activas en estas operaciones.
}

REVESCO No 109 - MONOGRÁFICO: La financiación complementaria y la respuesta de la economía social: la situación del "des-crédito" bajo la crisis financiera -

ISSN: 1885-8031 - www.ucm.es/info/revesco 
sociedades no financieras (panel superior), a los hogares para adquisición de vivienda (panel central) y para consumo y otros fines (panel inferior).

Por lo que se refiere, en primer lugar, al crédito a sociedades no financieras, sus condiciones son, en general, más restrictivas desde el inicio de la crisis, respecto a períodos anteriores.

En efecto, desde 2004 a mediados de 2007, los criterios de aprobación por las entidades financieras fueron relativamente laxos, lo que se constata por un valor del indicador negativo, que determina unas condiciones para la aprobación más favorables en el trimestre correspondiente respecto a las existentes en el inmediatamente anterior, y si bien, esa relajación es muy ostensible hasta el primer trimestre de 2005, en el que una buena parte de las entidades encuestadas manifiestan haber facilitado esas condiciones, ese carácter se mantiene, aunque disminuyendo el número de entidades que lo facilitaron, hasta el último trimestre de ese año, momento en el que prácticamente se mantienen los criterios de aprobación hasta el primer trimestre de 2007. Desde entonces, esos criterios para el crédito a las sociedades no financieras se han endurecido, de forma muy acusada hasta 2009, y luego, aún siendo restrictivas las condiciones, se comienzan a estabilizar a partir de 2010, en el que, salvo un cambio entre el primer y el segundo trimestre, los criterios de aprobación no han cambiado en un trimestre respecto al anterior.

En el caso de los hogares, las condiciones para la aprobación de los créditos por las entidades participantes en la encuesta, ya se empezaron a endurecer antes de 2007, existiendo un número mayor de entidades que informan de esas mayores restricciones en la concesión de estos créditos, afectando, más o menos, por igual con independencia del destino de los mismos (adquisición de vivienda y consumo y otros fines), si bien todavía se mantienen condiciones más duras en los créditos inmobiliarios.

No obstante, si comparamos la situación de estos criterios de aprobación en España con los existentes en el conjunto de la Unión Monetaria, no existen excesivas discrepancias, aunque sí un hecho destacable; así, mientras que, en el intervalo comprendido aproximadamente entre mediados de 2006 (salvo para los créditos al consumo y otros fines, en los que el inicio es en 2007) y primer trimestre de 2009, esos criterios se endurecieron más

REVESCO No 109 - MONOGRÁFICO: La financiación complementaria y la respuesta de la economía social: la situación del "des-crédito" bajo la crisis financiera -

ISSN: 1885-8031 - www.ucm.es/info/revesco 
significativamente en España (salvo en los correspondientes a las sociedades no financieras, que, si bien más duros en nuestro país, se aproximaron bastante), antes y después de este intervalo, los criterios en general han sido más exigentes en el conjunto de la UEM.

REVESCO No 109 - MONOGRÁFICO: La financiación complementaria y la respuesta de la economía social: la situación del "des-crédito" bajo la crisis financiera -

ISSN: 1885-8031 - www.ucm.es/info/revesco 
Gráfico 14. Variación de los criterios de aprobación de los créditos al sector privado no financiero (a) (b)
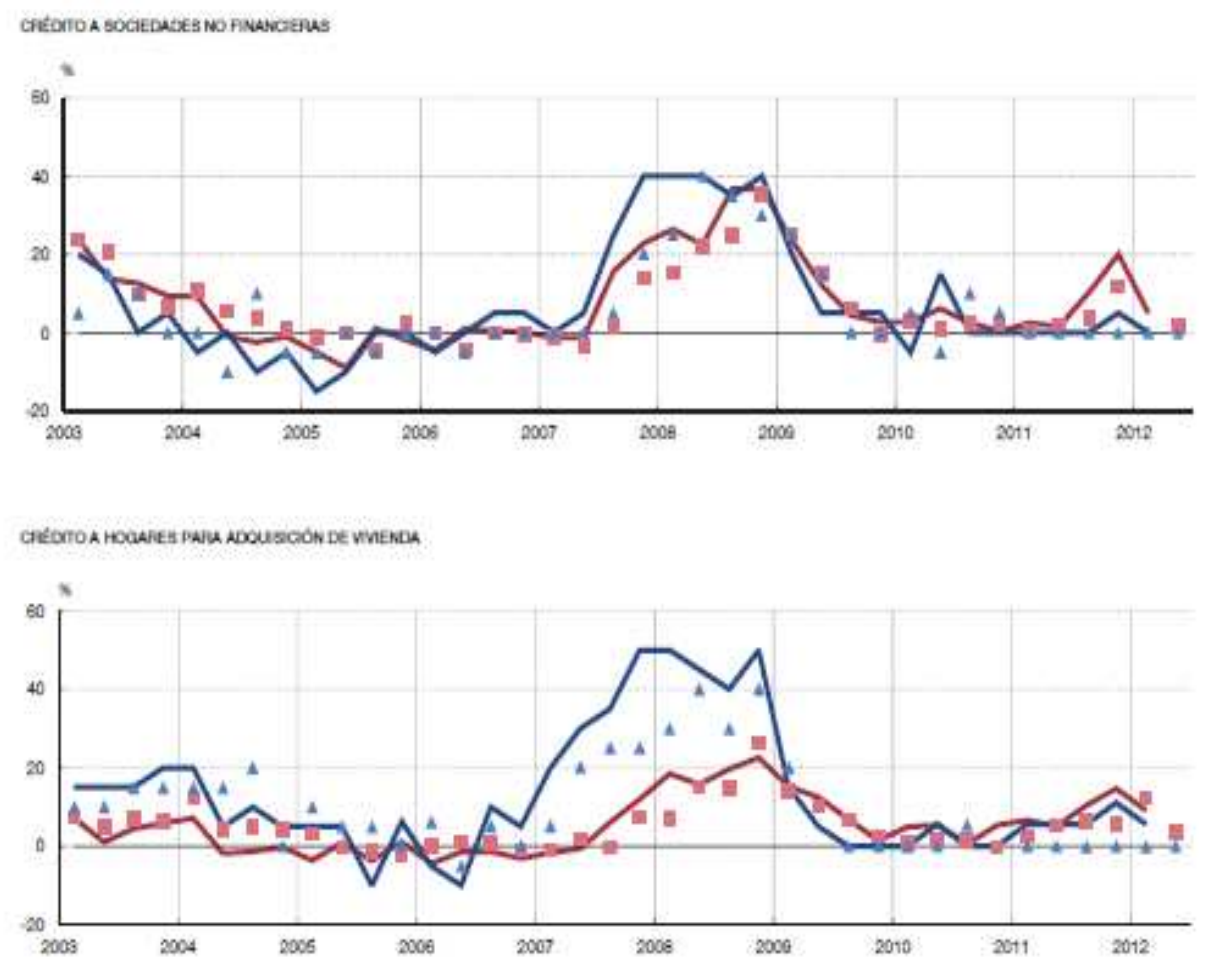

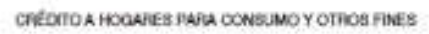

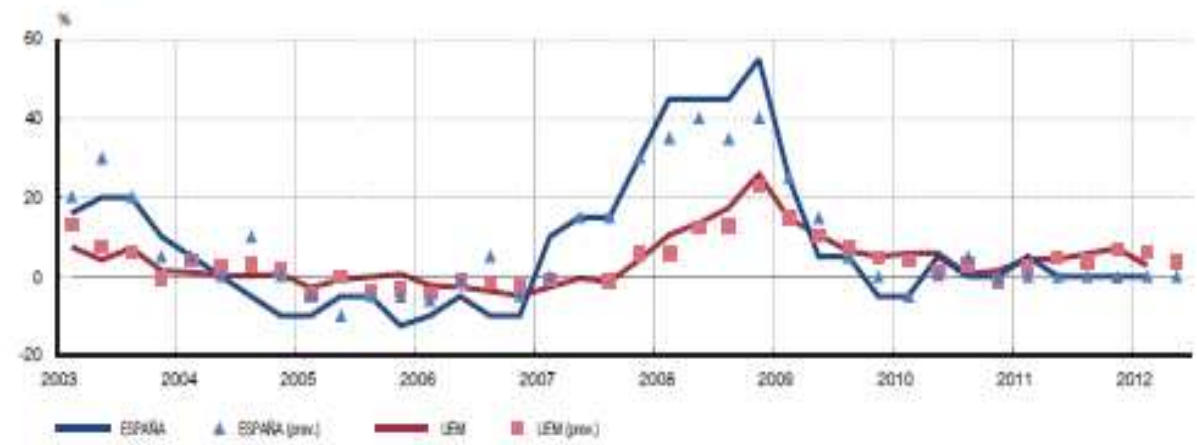

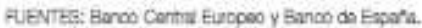

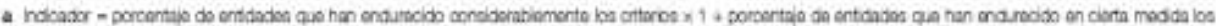

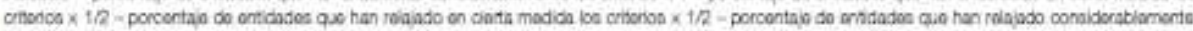
lon ontarion $x 1$.

En el Gráfico 15 recogemos ahora las variaciones en la demanda de préstamos bancarios también de las sociedades no financieras y de los hogares (éstos igualmente

REVESCO No 109 - MONOGRÁFICO: La financiación complementaria y la respuesta de la economía social: la situación del "des-crédito" bajo la crisis financiera -

ISSN: 1885-8031 - www.ucm.es/info/revesco 
separando los destinados a la adquisición de vivienda y los dirigidos al consumo y otros fines).

De nuevo, desde la perspectiva de la demanda del crédito por el sector privado no financiero de nuestro país, se observa una evolución condicionada por la crisis iniciada en 2007, aunque con algunas diferencias respecto a los resultados que hemos obtenido por los criterios de aprobación aplicados por las entidades financieras. Así, la caída en la demanda de crédito por los hogares presenta algunos cambios respecto a la correspondiente a las sociedades no financieras: en primer lugar, el inicio de la percepción de esa caída por parte de las entidades encuestadas se produce antes, pues ya empiezan algunas a observarla desde 2006 (mientras que en las empresas no financieras se constata en el inicio de la crisis); en segundo, la caída percibida en la demanda de créditos es bastante mayor en el sector hogares, y algo superior en las solicitudes de préstamos hipotecarios; y, en tercero, aunque el inicio de la recuperación de esa demanda de peticiones se produce en período similar (finales de 2008principios de 2009), resulta más estable en las sociedades no financieras, pues desde 2010 las entidades encuestadas no perciben grandes cambios en esa demanda (aunque sí una cierta caída en el primer trimestre de 2012), y más errática en los hogares, aunque hay un predominio de entidades encuestadas que observan una caída permanente de esa demanda en un trimestre respecto al anterior.

REVESCO Nº 109 - MONOGRÁFICO: La financiación complementaria y la respuesta de la economía social: la situación del "des-crédito" bajo la crisis financiera -

ISSN: 1885-8031 - www.ucm.es/info/revesco 
Gráfico 15. Variación en la demanda de créditos por el sector privado no financiero (a) (b)

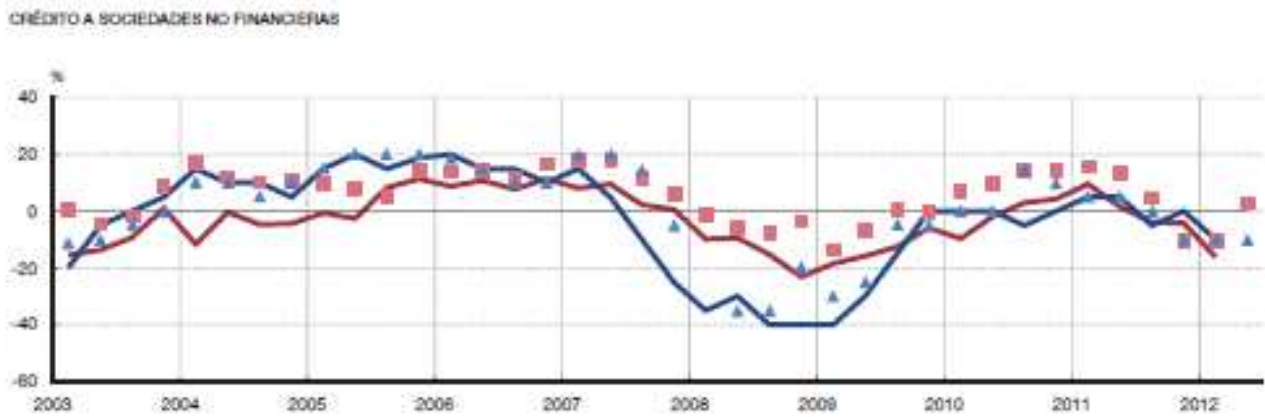

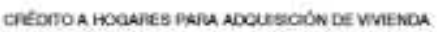

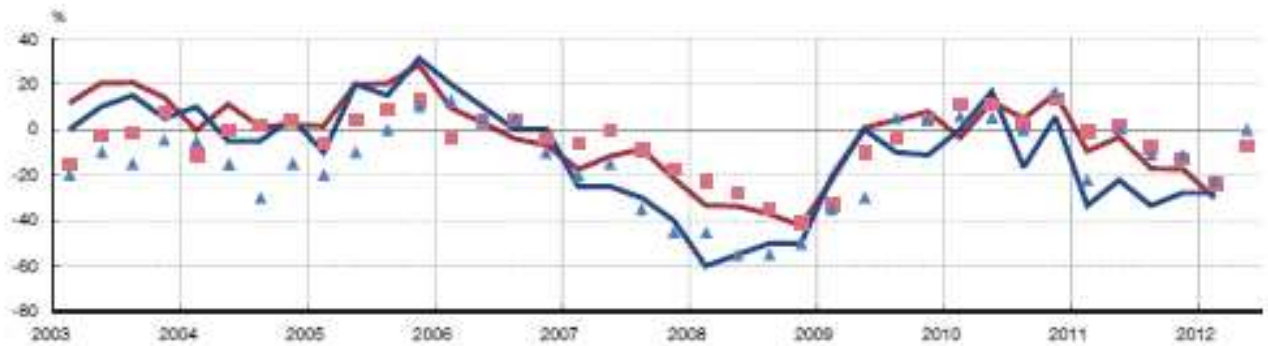

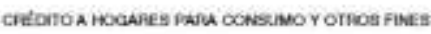

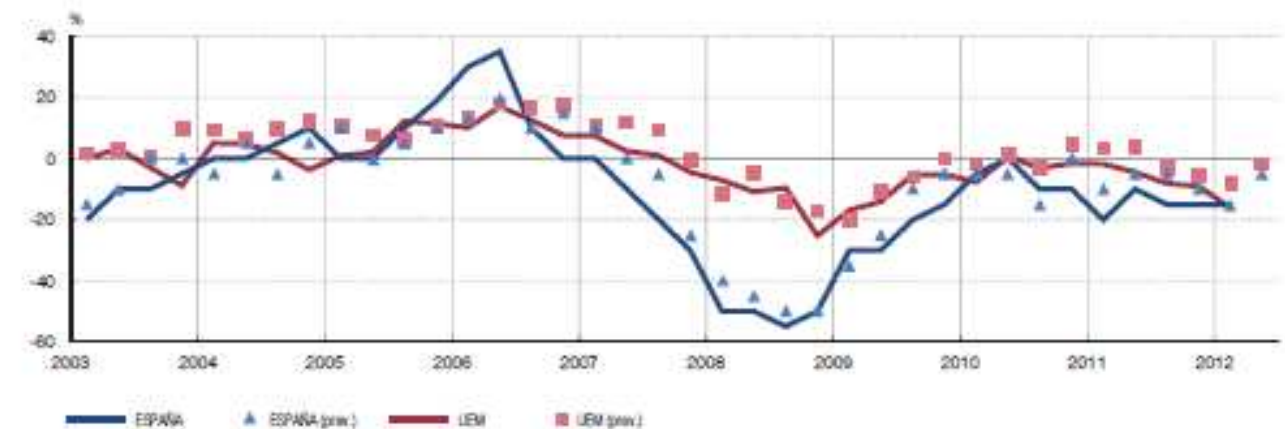

HeEVrest Burco Centud Furscoo y Banco do Eapora.

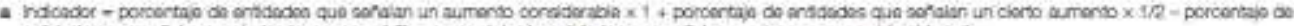

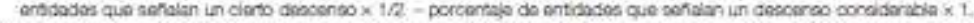

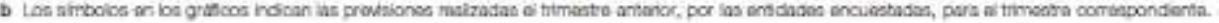

Si comparemos con el conjunto de la UEM, en términos generales, desde el inicio de la crisis las entidades participantes en la encuesta para toda la eurozona han observado una menor caída en la demanda de préstamos que en nuestro país, si bien, entre 2009 y 2010, según al crédito al que hagamos referencia, las diferencias en la demanda se han hecho más reducidas.

REVESCO No 109 - MONOGRÁFICO: La financiación complementaria y la respuesta de la economía social: la situación del "des-crédito" bajo la crisis financiera -

ISSN: 1885-8031 - www.ucm.es/info/revesco 
Además de la perspectiva de las entidades financieras, que nos otorga la Encuesta de Préstamos Bancarios que acabamos de analizar, es conveniente visualizar la percepción de la otra parte del mercado, la demandante de fondos. En este sentido, la encuesta periódica de las Cámaras de Comercio sobre el acceso de las pymes a la financiación ajena, nos permite una visión complementaria de la obtenida con anterioridad (Consejo Superior de Cámaras, 2012).

En esta encuesta se destaca las dificultades para la obtención de esa financiación, pues entre 2010 y 2011, poco más de 2/3 de las solicitudes realizadas (69,3\%) fueron atendidas por las entidades de crédito, habiéndose incluso deteriorado la situación en los últimos trimestres (66\% en el primero de 2012 y 62,3\% en el segundo), siendo la causa más esgrimida en la encuesta el endurecimiento de las condiciones del crédito, pues en las concedidas, las empresas receptoras confiesan que han tenido que aceptar unas condiciones más duras, con un coste de financiación más alto para un 80\% de las beneficiarias (cuando en el promedio 20102011 lo fue para el 65,1\%), y unas exigencias de avales y garantías superiores $(84,8 \%$ frente al 81,9\% en el promedio de 2010-2011).

Así pues, a partir de los datos analizados, la caída en el crédito en nuestro país desde el inicio de la crisis económica actual responde a factores tanto de oferta como de demanda (Banco de España, 2012). Por un lado, las entidades de crédito han endurecido, más intensamente en los primeros años de la misma, los criterios para su aprobación; por otro, el sector privado no financiero también ha reducido, más significativamente si cabe, su demanda de préstamos, mayormente los hogares. La conjunción de ambos fenómenos se ha traducido en la caída general del crédito que hemos indicado ya en nuestro trabajo y, por tanto, las posibilidades futuras de recuperación del mismo, deben descansar en ambas vertientes: así, una recuperación económica general deberá traducirse en una mayor demanda de financiación crediticia; pero también unas ciertas mayores facilidades para la concesión de esos créditos alentará la recuperación de esta variable.

\section{CONCLUSIONES}

La economía española viene registrando, al igual que otras economías, ciclos crediticios, con fases de auge y de recesión, que mantienen una estrecha relación con la evolución de la actividad económica. Sin embargo, el último ciclo del crédito en España

REVESCO No 109 - MONOGRÁFICO: La financiación complementaria y la respuesta de la economía social: la situación del "des-crédito" bajo la crisis financiera -

ISSN: 1885-8031 - www.ucm.es/info/revesco 
resulta muy diferente a los anteriores, en tanto en cuanto se ha desviado notablemente de la tendencia seguida por el PIB. En efecto, el crecimiento del crédito en el período 2003-2007 ha sido muy superior al de la economía española, originándose un boom crediticio, que se ha visto truncado por el inicio de la crisis económica y financiera.

Ese período de expansión del crédito bancario ha ido asociado de un fuerte endeudamiento del sector privado no financiero, con niveles superiores a los de la mayor parte de los países de nuestro entorno, para lo cual las entidades bancarias han tenido que recurrir a la financiación en el exterior al no disponer el mercado interno de un nivel de ahorro suficiente para atenderlo. Ello ha provocado que, cuando la crisis se inicia, y los mercados reducen significativamente su oferta de fondos, no se haya podido alimentar el crédito, y que muchas entidades bancarias españolas empezaran a manifestar serias dificultades.

Detrás de esta evolución del crédito durante los últimos años se encuentra la participación de todas las entidades bancarias, incluidas las de carácter social, y en especial, las cajas de ahorros, cuya participación en el volumen total para la financiación a actividades productivas, y en el destinado a la industria, y fundamentalmente a la construcción, ha ido aumentado a lo largo de lo que se llevaba de siglo XXI. Esa dependencia en sus operaciones activas de la financiación al sector de la construcción ha sido uno de los elementos que han favorecido esa mayor situación de crisis del sector de las cajas de ahorros en España, obligando a su reestructuración, y que también ha afectado a las cooperativas de crédito, que han conocido igualmente cambios sustanciales en su estructura y organización.

Por último, se ha puesto de manifiesto que la caída del crédito que se produce en nuestro país a raíz de la crisis financiera responde a factores tanto por el lado de la oferta como por el lado de la demanda; es decir, las restricciones crediticias han venido determinadas tanto porque las entidades bancarias han venido endureciendo los criterios para la concesión de la financiación a su clientela, como porque la demanda también se ha resentido.

Una recuperación sostenida de la economía española requiere pues una recuperación del crédito, para lo cual es preciso que la demanda se reactive, lo cual se favorece sin duda en la medida en que la actividad económica mejore, pero también que se produzca una

REVESCO No 109 - MONOGRÁFICO: La financiación complementaria y la respuesta de la economía social: la situación del "des-crédito" bajo la crisis financiera -

ISSN: 1885-8031 - www.ucm.es/info/revesco 
suavización por parte de las entidades bancarias de los requisitos que vienen exigiendo para la concesión de los préstamos.

\section{BIBLIOGRAFÍA}

ALBEROLA, E. y J.C. BERGANZA, "La recuperación del crédito bancario en América Latina”, Boletín Económico, Banco de España, febrero 2007, págs. 73-85.

ANGUREN, R., "Identificación y evolución de los ciclos de crédito en las economías avanzadas", Revista de Estabilidad Financiera, N.22, Banco de España, mayo 2012, págs. 125-139.

BANCO CENTRAL EUROPEO, "Evolución reciente de los préstamos al sector privado", Boletín Mensual, enero 2011, págs. 61-78.

BANCO CENTRAL EUROPEO, "El crecimiento del dinero y del crédito después de crisis económicas y financieras: una perspectiva histórica mundial”, Boletín Mensual, febrero 2012, págs. 77-95.

BANCO DE ESPAÑA, “Informe anual, 2011”, Banco de España, junio 2012.

BANCO DE ESPAÑA, "Encuesta a empresas no financieras sobre condiciones de acceso al crédito”, Boletín Económico, mayo 2009, págs. 59-70.

CALVO, A., PALOMO, R.J. y GUTIÉRREZ, M., "El panorama actual del sistema financiero", en Campuzano, A.B. y Palomo, R.J. (coord.), Los mercados financieros, Ed. Tirant lo Blanch, Valencia, 2012.

CLAESSENS, S., M. AYHAN K. y M.E. TERRONES, “A recovery without credit: Possible, but ...", Vox EU. org, mayo 2009.

CONSEJO SUPERIOR DE CÁMARAS, "Encuesta de las Cámaras sobre el acceso de las PYMES a la financiación ajena. Resultados del $2^{\circ}$ trimestre de 2012”, Madrid, 2012.

GUAL, J., "El carácter procíclico del sistema financiero", Revista de Estabilidad Financiera, №.16, Banco de España, mayo 2009, págs. 23-40.

MULINO, M., "Encuesta sobre préstamos bancarios en España: abril de 2012”, Boletín Económico, Banco de España, mayo 2012, pp. 21-32.

REVESCO No 109 - MONOGRÁFICO: La financiación complementaria y la respuesta de la economía social: la situación del "des-crédito" bajo la crisis financiera -

ISSN: 1885-8031 - www.ucm.es/info/revesco 